University of Rhode Island

DigitalCommons@URI

Open Access Master's Theses

2014

\title{
BIOLOGICAL INDICATORS FOR ASSESSING FRESHWATER WETLAND CONDITION IN RHODE ISLAND
}

Thomas E. Kutcher

University of Rhode Island, tomkutcher@my.uri.edu

Follow this and additional works at: https://digitalcommons.uri.edu/theses

\section{Recommended Citation}

Kutcher, Thomas E., "BIOLOGICAL INDICATORS FOR ASSESSING FRESHWATER WETLAND CONDITION IN RHODE ISLAND" (2014). Open Access Master's Theses. Paper 308.

https://digitalcommons.uri.edu/theses/308

This Thesis is brought to you for free and open access by DigitalCommons@URI. It has been accepted for inclusion in Open Access Master's Theses by an authorized administrator of DigitalCommons@URI. For more information, please contact digitalcommons-group@uri.edu. 
BIOLOGICAL INDICATORS FOR ASSESSING FRESHWATER WETLAND CONDITION IN RHODE ISLAND

BY

THOMAS E. KUTCHER

A THESIS SUBMITTED IN PARTIAL FULFILLMENT OF THE REQUIREMENTS FOR THE DEGREE OF MASTER OF SCIENCE

IN

BIOLOGICAL AND ENVIRONMENTAL SCIENCES

UNIVERSITY OF RHODE ISLAND

2014 


\section{MASTER OF BIOLOGICAL AND ENVIRONMENTAL SCIENCES}

$\mathrm{OF}$

THOMAS E. KUTCHER

APPROVED:

Thesis Committee:

Major Professor: Graham E. Forrester

Keith T. Killingbeck

Richard A. McKinney

Nasser H. Zawia

DEAN OF THE GRADUATE SCHOOL

UNIVERSITY OF RHODE ISLAND

2014 


\begin{abstract}
There is a growing need to identify assessment methods that can provide managers and researchers with a relative indication of wetland condition. Biological indicators (bioindicators) are considered to be the most effective and precise indicators of environmental condition. This study focuses on the development of bioindicators based on the concept of species conservatism, or intolerance to human disturbance. In theory, the aggregate conservatism of a species assemblage should indicate the environmental quality of a natural area. In the first part of this study, I applied the conservatism concept to adult Odonata composition to create a novel bioindicator for open-canopy wetland systems. I used an extensive existing Odonata dataset to develop a conservatism-based Odonata index of wetland integrity and test it against rapid assessment and landscape-scale reference measures. The Odonata index was well predicted by both reference measures and showed no evidence of dependence on sampling effort, wetland size, or geomorphic class. My findings suggest that conservatism of adult Odonata averaged across species may provide a robust indicator of freshwater wetland integrity that is practical for wetland assessment.

The conservatism concept is more typically applied to Floristic Quality Assessment (FQA), using vascular plant species. FQA index variants incorporating species richness, nativeness, and abundance have been empirically tested as indicators of freshwater wetland integrity, but less attention has been given to clarifying the mechanisms controlling FQA functionality; consequently, disagreement remains in identifying the most effective variant. In the second part of this study, I tested commonly-used FQA variants against landscape, rapid, and biological reference
\end{abstract}


measures in open canopy wetlands. FQA variants incorporating species richness did not correlate with any reference measures and were influenced by wetland size and hydrogeomorphic class. In contrast, FQA variants disregarding species richness showed strong, monotonic relationships with all three reference measures, independent of wetland size and class. Incorporating non-native species improved performance over using only native species, and incorporating relative species abundance improved performance further. Non-richness variants responded linearly to individual and aggregate stresses, suggesting broad response to cumulative degradation, or decreasing integrity. These findings support the following recognized theories: aggregate plant species conservatism declines with increased disturbance; plant species richness increases with intermediate disturbance and increasing unit area; non-native species are favored by human disturbances; and the proportional abundance of species is an important functional component of ecosystem health. This suggests that an abundanceweighted FQA variant incorporating non-native species and disregarding species richness should provide the most highly-relevant and effective FQA measure of ecological integrity for open-canopy vegetated wetlands. 


\section{ACKNOWLEDGMENTS}

I sincerely thank my major professor Graham Forrester, my committee members Rick McKinney and Keith Killingbeck, and my committee chair Caroline Gottschalk Druschke for their considerable guidance and input. I thank Jason Bried for generously sharing his expertise on Odonata and statistics. I also thank Carolyn Murphy, Ginger Brown, Evan Preisser, Q. Kellogg, and Peter Paton for providing technical advice. David Gregg, Susan Kiernan, and Carolyn Murphy administered this work and Deanna Levanti, Stacey Liecht Young, Rick Enser, and Grace Lentini assisted with field work and data entry. Special thanks to my family for their patience and support. I conducted this work during my employment with the Rhode Island Natural History Survey, which is housed by the University of Rhode Island, College of the Environment and Life Sciences. This project was funded by the Rhode Island Department of Environmental Management, Office of Water Resources, through a Wetlands Program Development Grant awarded by the United States Environmental Protection Agency. 


\section{PREFACE}

This thesis was written in the manuscript format as stipulated by the Graduate School at the University of Rhode Island, Kingston, Rhode Island. Chapter 1, Adult Odonata conservatism as an indicator of freshwater wetland condition, is formatted for publication in Ecological Indicators and was published in March 2014. Chapter 2, The ecological mechanisms driving floristic quality assessment of wetland integrity, is formatted for upcoming submission to Ecological Applications. 


\section{TABLE OF CONTENTS}

ABSTRACT ....................................................................................................................

ACKNOWLEDGMENTS ............................................................................................. iv

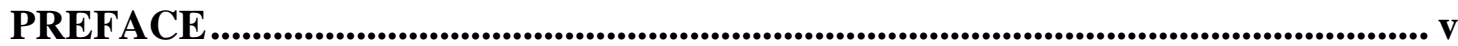

TABLE OF CONTENTS....................................................................................................... vi

LIST OF TABLES .................................................................................................................... vii

LIST OF FIGURES ….................................................................................................. ix

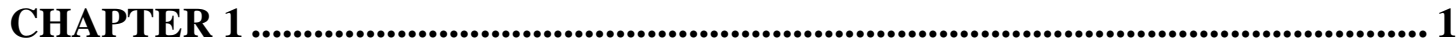

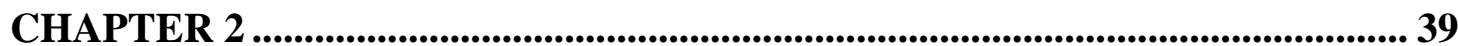

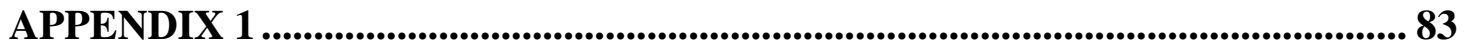




\section{LIST OF TABLES}

\section{Chapter 1}

Table 1. Components of the Rhode Island Rapid Assessment Method for evaluating

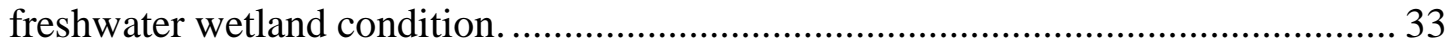

Table 2. Coefficients of conservatism (CoC) for 135 Odonata species known to occur in Rhode Island and the number of training sites where each was collected ............. 34

Table 3. Odonata Index of Wetland Integrity (OIWI) values and effort data from 51 wetland assessment units in Rhode Island 35

Table 4. Confidence limits (2.5th and 97.5th percentiles) of linear model fit between individual RIRAM metrics (see Table 1) and the OIWI based on computer-intensive resampling (1,000 iterations) 36

\section{Chapter 2}

Table 1. Variants of the FQAI formula and their recent applications in freshwater wetland assessment. 76

Table 2. Values of floristic, Odonata, rapid, and landscape assessment indices of freshwater wetland condition from 20 wetland assessment units

Table 3. Spearman rank correlation coefficients and probability values comparing various floristic measures against reference measures of freshwater wetland condition among 20 wetland assessment units 78

Table 4. Kruskal-Wallace H-values (non-parametric analog to ANOVA) and Spearman rank correlation coefficients (rs) comparing measures of freshwater wetland condition against hydrogeomorphic class $(n=3)$ and unit size $(n=20)$, among 20 freshwater wetland assessment units 
Table 5. Significant Spearman rank correlation coefficients comparing best-fit floristic measures with RIRAM metrics and submetrics among 20 wetland assessment units,

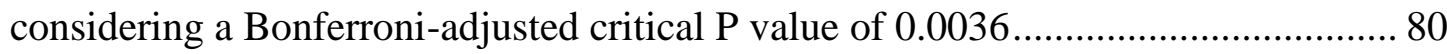

Table 6. Spearman rank correlation coefficients comparing reduced-effort floristic measures against existing measures of freshwater wetland condition among 20 reference wetland units 


\section{LIST OF FIGURES}

\section{Chapter 1}

Figure 1. Performance of the OIWI: Odonata Index of Wetland Integrity for 51 wetland sites in relation to the Rhode Island Rapid Assessment Method and \% impervious surface area (measured in a 305-m buffer around each site) 37 Figure 2. Discriminating among disturbance designations: Box and whisker plots depicting the distribution of OIWI values $(n=51)$ in relation to three reference designations derived from RIRAM and ISA values, respectively 38

\section{Chapter 2}

Figure 1. Box plots depicting the distributions of FQA index values among RIRAM and ISA-based reference designations of freshwater wetland condition for 20 wetlands 


\title{
CHAPTER 1
}

Published in Ecological Indicators, March 2014

\section{Adult Odonata conservatism as an indicator of freshwater wetland condition}

\author{
Thomas E. Kutcher ${ }^{\mathrm{a}, \mathrm{c}, \mathrm{d}}$ and Jason T. Bried ${ }^{\mathrm{b}}$ \\ ${ }^{a}$ Rhode Island Natural History Survey, University of Rhode Island, 200 Ranger Hall, \\ Kingston, RI 02881, USA \\ ${ }^{\mathrm{b}}$ Department of Zoology, Oklahoma State University, 501 Life Sciences West, \\ Stillwater, OK 74078, USA \\ ${ }^{\mathrm{c} C u r r e n t}$ address: Department of Natural Resources Science, University of Rhode \\ Island, Coastal Institute, Kingston, RI 02881, USA \\ ${ }^{\mathrm{d}}$ Corresponding author: Tel.: 401-536-4352; E-mail address: tomkutcher@my.uri.edu
}




\begin{abstract}
There is a growing need to identify effective and efficient biological indicators for wetland assessment, and adult damselflies and dragonflies (Insecta: Odonata) possess several attributes that make them attractive for this application. We introduce a general indicator of freshwater wetland condition based on objectively estimated adult Odonata species conservatism, or sensitivity to human disturbances. We used an extensive opportunistic survey dataset from Rhode Island (USA) to empirically assign a coefficient of conservatism (CoC) to each of 135 Odonata species, based on their exclusivity to categories of degradation among 510 wetlands; the mean $\mathrm{CoC}$ of species observed in the adult stage was applied as an index of wetland integrity. An independent sample of 51 wetlands was also drawn from the opportunistic survey to test the performance of the index relative to human disturbance, as measured by multimetric rapid assessment and surrounding impervious surface area. The index was well predicted by both disturbance measures and showed no evidence of dependence on sampling effort, wetland size, or geomorphic class. Our findings suggest that conservatism of adult Odonata averaged across species may provide a robust indicator of freshwater wetland condition. And because adult Odonata are generally easy to identify, especially relative to larval Odonata, the index could be particularly useful for wetland assessment. Our straightforward empirical approach to $\mathrm{CoC}$ estimation could be applied to other existing spatially-referenced Odonata datasets or to other species assemblages.

Keywords: Biological indicator; Damselfly; Dragonfly; Rapid assessment; Rhode Island; Wetland assessment
\end{abstract}




\section{Introduction}

Biological indicators (or bioindicators) can provide reliable, quantitative characterizations of ecological condition, and there is a growing need to identify effective bioindicators for use in wetlands management and protection (Sifneos et al., 2010; U.S. EPA, 2002). Macroinvertebrates have long been recognized as useful bioindicators for aquatic and wetland ecosystems (Hilsenhoff, 1977; Karr and Chu, 1999; Rader et al., 2001; Wissinger, 1999), but the impracticalities of collecting, sorting, and identifying aquatic stages limit their use in rapid assessments (Cummins and Merritt, 2001; King and Richardson, 2002; Turner and Trexler, 1997). It is therefore worthwhile to evaluate taxa and life stages that are both ecologically important and logistically feasible for bioassessment. Aerial stages of aquatic macroinvertebrates are important for species dispersal and the transfer of energy across aquatic and upland systems and among trophic levels (Malmqvist, 2002; Sanzone et al., 2003), and are more sensitive than the aquatic stages to land use practices around wetlands (Anderson and Vondracek, 1999; Raebel et al., 2012; Tangen et al., 2003).

Dragonflies and damselflies (Odonata) are prominent in many freshwater habitats and may contribute a large proportion of total invertebrate biomass and species richness (e.g., Batzer et al., 1999; Blois-Heulin et al., 1990; Rader et al., 2001; Sang and Teder, 2011; Wittwer et al., 2010). Odonates are sensitive to conditions at the breeding site and surrounding terrestrial area, can react quickly to changes in environmental quality via active dispersal, and contain a tractable number of species for practical use (Chovanec and Waringer, 2001; Oertli, 2008). Adult odonates are 
conspicuous over water and relatively easy to identify at the species level (Bried et al., 2012a; Oertli, 2008; Raebel et al., 2010), and may be especially well suited for broad and integrative assessments of the wetland breeding site and surrounding landscape (Bried and Ervin, 2006; Dolný et al., 2012; Foote and Hornung, 2005; Foster and Soluk, 2006; Reece and McIntyre, 2009). Adult odonates are therefore well-suited for rapid assessment methods (Fennessy et al., 2007) and addressing the increased focus on wetland quality and not just quantity in the United States (Scozzafava et al. 2011).

Odonata are already established as focal organisms for freshwater conservation (Samways, 2008) and as good indicators of site value and habitat quality for ponds, lakes, rivers, and streams (Butler and deMaynadier, 2008; Chovanec et al., 2002; D’Amico et al., 2004; Flenner and Sahlén, 2008; Primack et al., 2000; Raebel et al., 2012; Remsburg and Turner, 2009; Rosset et al., 2013; Silva et al., 2010).

Bioassessment tools based on adult Odonata have been developed and tested in Europe and South Africa. Chovanec and Waringer (2001) combined species-specific abundance classes, niche width, and habitat preference into an Odonata Habitat Index meant to classify the ecological status of river-floodplain systems in Austria. Simaika and Samways (2009) combined species' geographical range, risk of extinction, and sensitivity to habitat change into a Dragonfly Biotic Index that has been effective for assessing river condition in South Africa (Simaika and Samways, 2011) and the conservation value of ponds and small lakes in Europe and South Africa (Rosset et al., 2013). These approaches show potential for assessing wetland condition, but they have not been tested in that capacity, specifically. 
A reliable attribute in the biological assessment of environmental condition is species conservatism, referring to the relative sensitivity (vulnerability) of different species to habitat degradation (Cohen et al., 2004; Lopez and Fennesy, 2002; Miller and Wardrop, 2006). Conservatism is commonly associated with floristic quality assessment, wherein a coefficient of conservatism (CoC) ranging from 0 to 10 is assigned to vascular plant species, based on the expert opinion of a team of botanists. High $\mathrm{CoC}$ are given to species that are relatively sensitive to habitat degradation, whereas low $\mathrm{CoC}$ are assigned to species that are non-native or highly tolerant. The collective conservatism of a species assemblage should, in theory, reflect the ecological condition of a given area (Swink and Wilhelm, 1979; Taft et al., 1997). In the United States, interest in developing and applying $\mathrm{CoC}$ for the assessment of wetland condition is rapidly growing (Bried et al., 2012b); yet to date, conservatism has been applied almost exclusively in the context of floristic quality (e.g., Bried et al., 2013; Cohen et al., 2004; Cretini et al., 2012; Ervin et al., 2006; Lopez and Fennesy, 2002; Medley and Scossafava, 2009; Matthews et al., 2005; Miller and Wardrop, 2006; but see Micacchion, 2004).

In this study we apply the conservatism concept to adult Odonata. We use an extensive opportunistic survey dataset to introduce an objective, empirical method of assigning $\mathrm{CoC}$ based on species occurrence and exclusivity to categories of wetland degradation. We then aggregate the $\mathrm{CoC}$ into an index of freshwater wetland condition, and evaluate index performance using independent odonate data and metrics of human disturbance. 


\section{Materials and methods}

\subsection{Data}

We conducted our study in Rhode Island located in the northeastern United States. We relied on data from the Rhode Island Odonata Atlas Project (hereafter “Atlas") for this study. The Atlas was conducted from 1999 through 2004 as a statewide inventory of adult Odonata administered by the Rhode Island Natural History Survey and the Rhode Island Chapter of The Nature Conservancy (Brown and Briggs, in prep.). Professionals and trained volunteers catalogued 135 Odonata species throughout Rhode Island, collecting 13,000 verified voucher specimens across 1,090 aquatic, wetland, and upland sites. As with other citizen-based statewide Odonata inventory projects (e.g., White et al., 2010) or any opportunistic atlas-type surveys (Robertson et al., 2010), sampling effort was not standardized over time or space.

\subsection{Generation of $\mathrm{CoC}$ and the wetland integrity index}

Assignment of CoC using expert judgment relies on specific knowledge of species distributions relative to the degradation of their habitats. Subjectivity and bias are introduced by the limitations of experience, a focus on geographic or habitat range, perception of habitat degradation, and interpretation of the $\mathrm{CoC}$ designations (Bried et al., 2012b). To avoid these problems, we generated Odonata CoC empirically, using georeferenced point records from the Atlas and a Geographic Information System (GIS).

We assigned the CoC based on species' occurrences among freshwater wetlands. To account for dataset spatial inaccuracies and increase the likelihood that 
sampling points were associated specifically with wetlands, only points that occurred within or near $(<50 \mathrm{~m})$ previously mapped wetlands were considered. Points associated with unvegetated surface waters or uplands were excluded from analysis. Qualified points were assumed to be representative wetlands, and were sorted by the proportion of developed and agricultural land within $300 \mathrm{~m}$. Points in the lower quartile were selected as least-disturbed wetlands, points in the upper quartile as mostdisturbed wetlands, and an equal number of points surrounding the median as intermediately-disturbed wetlands; this resulted in a training sample of 510.

Following the indicator species analysis proposed by Dufrene and Legendre (1997), a CoC was determined for each species by:

$$
\left[\frac{N_{L D}}{N}+\left(1-\frac{N_{M D}}{N}\right)\right] \div 2 \times 10
$$

where $N_{L D}$ is the number of least-disturbed wetlands in which a given species was detected, $N_{M D}$ is the number of most-disturbed wetlands where that species was detected, and $N$ is the total number of wetlands (including intermediately-disturbed sites) where that species was detected. This approach averages the "affinity" for leastdisturbed wetlands and the inverse affinity for most-disturbed wetlands, multiplying by 10 to scale the output to the traditional $\mathrm{CoC}$ scale of floristic quality assessment. Thus the $\mathrm{CoC}$ range from 0 if a species occurs exclusively in the most-disturbed group to 10 if a species occurs exclusively in the least-disturbed group. In line with recommendations for floristic quality assessment (e.g., Bried et al., 2013; Rooney and 
Rogers, 2002; Taft et al., 2006), we recommend the mean CoC of all species found at a particular wetland site as an Odonata Index of Wetland Integrity (OIWI).

\subsection{Index performance}

To evaluate the OIWI, we used a sample of Atlas wetlands that was independent of the training sample described above. Prior to extracting the training sample, we isolated wetland features that were surveyed at least three times and produced at least 10 specimens over the Atlas project period. From that subset, we selected 51 study sites spanning a gradient of surrounding land use intensity. We used photointerpretation of recent leaf-off, high-resolution aerial imagery to delineate a polygonal wetland assessment unit for each study site according to Kutcher (2011). Wetland assessment units ranged in size from 0.12 to 36 ha with an average of 5.3 ha. Many (43) of the units contained multiple vegetation classes. The most frequently represented vegetation classes (per Cowardin et al., 1979) within the study sample were Emergent Wetland (40 sites), Forested Wetland (37 sites), and Shrub Swamp (36 sites), and the most common hydrogeomorphic settings (modified from Brinson, 1993) were Connected Depression (16 sites), Isolated Depression (16 sites), and Floodplainriverine (16 sites).

We tested the OIWI against the Rhode Island Rapid Assessment Method, or RIRAM (Kutcher, 2011), which follows federal guidelines for establishing reference conditions for wetlands (Faber-Langendoen et al., 2009; U.S. EPA, 2002). This evidence-based tool produces a relative index of freshwater wetland condition and focuses on estimation, rather than interpretation, to maximize objectivity. RIRAM 
scoring is based on the premise that diverse human disturbances additively contribute to the degradation of general wetland condition (Fennessy et al., 2007; U.S. EPA, 2006). Metrics of buffer integrity (2 metrics), in-wetland stress (7 metrics), and functional integrity (1 metric) are summed to generate a single index based on 100 possible points, with each metric carrying ten points (Table 1). A RIRAM score of 100 indicates no observed stresses or impacts, whereas scores approaching 0 indicate a high degree of degradation, thus RIRAM decreases incrementally with an increase in perceived disturbance. We collected RIRAM data according to Kutcher (2011) at each of the 51 study sites.

Because RIRAM is inherently partly subjective, we also tested the OIWI against the proportion of impervious surface area (ISA) within the surrounding $305 \mathrm{~m}$ $(1000 \mathrm{ft})$ of each polygonal wetland unit in the study sample. The relative area of impervious surface provides an effective surrogate for human influence because it summarizes and reflects multiple effects of anthropogenic stress (Karr and Chu, 1997). We generated ISA directly from high-resolution impervious surface data (RIGIS, 2010), resulting in a coarse but objective disturbance measure to support our validation analysis.

\subsection{Statistical analysis}

Residuals from simple linear modeling of OIWI over RIRAM and ISA for the 51 wetlands showed clear heterogeneity and non-normality based on goodness-of-fit (Shapiro-Wilk test), residual by predicted plots (“cone-shaped” spread), and Q-Q plots (skewed left). For this reason, we used bootstrap resampling to evaluate the linear 
model fit for the OIWI versus RIRAM and ISA gradients and for the OIWI versus each RIRAM metric individually. We assumed a bootstrap approach would handle the zero-inflation inherent to some of the individual RIRAM metrics. Using Resampling Stats v4.0 (written by S. Blank, (O2012 statistics.com, Resampling Stats Inc., Arlington, VA), the data were sampled with replacement into a new set of cells, shuffling the rows as units. We then fit a simple linear model to this resampled data set and repeated and scored the model fit output (i.e., $\mathrm{R}^{2}$ or coefficient of determination) for 1,000 iterations. We report the $2.5^{\text {th }}$ and $97.5^{\text {th }}$ percentiles of the resampled distribution as a 95\% confidence interval for model fit (see also Bried et al., 2013).

The OIWI was further evaluated using box plots of OIWI distributions in relation to RIRAM and ISA reference designations, following Barbour et al. (1996). Reference designations were established using 25th and 75th percentile index values to identify most-disturbed (degraded) and least-disturbed (reference-standard) thresholds, respectively; all other study units were considered intermediatelydisturbed. The degree of overlap between interquartile ranges and medians of OIWI distributions was used to evaluate OIWI performance. Non-overlapping interquartile ranges within most and least-disturbed designations indicate high sensitivity to disturbance and excellent metric performance, whereas various degrees of interquartile-median overlap indicate lower sensitivity and performance (Barbour et al., 1996; Jacobs et al., 2010; Veselka et al., 2010).

\section{Results}

\subsection{CoC and index values}


Odonata $\mathrm{CoC}$ ranged from 0 to 10 with a mean $\pm \mathrm{SD}$ of $6.4 \pm 2.2$ (Table 2).

Species observed occurrence rates in the 510-site training sample ranged from zero to $23 \%$ with a median of about $3 \%$. Only one of the 135 documented Atlas species, Libellula auripennis, was not represented in the training sample; this was assigned a $\mathrm{CoC}$ of 10 , since it was observed only once during the Atlas inventory period at a minimally-disturbed site (based on $0 \%$ cultural land cover within $300 \mathrm{~m}$ ). Other rarely-represented species were assigned $\mathrm{CoC}$ following our methods. OIWI values generated with and without incorporating rarely observed species-i.e., those species with fewer than 20 site occurrences in the Atlas ( $n=28$ species), based on a natural break in the data and best professional judgment—were nearly identical (Spearman's rank-correlation test, $r_{s}=0.99, P<0.001, n=51$ study sites), suggesting that the inclusion of rare species is unlikely to strongly affect OIWI outcomes. Rare-species $\mathrm{CoC}$ were therefore retained in the OIWI to avoid introducing bias or circularity associated with culling rare species according to our best professional judgment or calibration with our disturbance gradients.

OIWI values ranged from 3.74 to 7.15 with a mean of $5.90 \pm 0.77$ among the 51 study sites (Table 3). Number of species recorded per site ranged from 4 (among 17 specimens collected across four site visits) to 47 (among 124 specimens collected across seven visits). We did not find evidence of association between OIWI values and measures of sampling effort per site, including number of specimens, number of visits, and number of species $\left(r_{s}=0.13-0.17, P=0.22-0.37\right)$. RIRAM scores ranged from 37.9 to 100 with a mean of $79.2 \pm 17.0$, and ISA ranged from 0 to $62.4 \%$ with a mean of $10.0 \pm 14.0 \%$, indicating a broad range of wetland conditions across the study 
sample. The OIWI, ISA, and RIRAM were each uncorrelated with wetland unit size $\left(r_{s}=-0.09-0.04, P=0.53-0.90\right)$.

\subsection{Index performance}

The OIWI was well predicted by the overall RIRAM gradient and showed evidence of a linear relationship with the impervious surface area measure (Fig. 1). OIWI also showed evidence of a linear relationship with many of the individual RIRAM metrics, including strong relationships with the buffer, landscape, and integrated functional ('Observed State') metrics (Table 4).

OIWI interquartile ranges within the most-disturbed and least-disturbed wetland categories, as determined by both RIRAM and ISA, did not overlap, and median OIWI values differed between those categories according to both indices (Fig 2; Mann-Whitney U-tests, $Z=-4.33$ and $-4.08, P<0.001)$. Additionally, the median OIWI in most-disturbed and least-disturbed wetlands differed from the median OIWI in intermediately-disturbed wetlands as determined by RIRAM $(Z=3.49$ and 4.60, $P$ $<0.001)$. There was no evidence that median OIWI or RIRAM values varied among connected depression, isolated depression, and floodplain-riverine geomorphic settings (Kruskal-Wallis test, $H=3.02, P=0.22$ and $H=1.07, P=0.59$, respectively), indicating that hydrogeomorphology did not strongly bias OIWI or RIRAM outcomes. Vegetation-based classes could not be an analyzed in this way because more than one type was often represented within a single study unit.

\section{Discussion}

\subsection{Index performance}


An effective indicator must separate human disturbance and degraded ecological condition from the inherent variation found in nature (Brazner et al., 2007; Karr and Chu, 1999; Swink and Wilhelm, 1979; Taft et al., 1997). Our study demonstrates the potential of a new index (OIWI) for freshwater wetland condition assessment built on the empirically estimated conservatism of adult odonate species. Correlations between OIWI and a multi-metric disturbance gradient (RIRAM) suggest that multiple stressors influence wetland patch use by odonate species. The stronger linear relationship with the full RIRAM than with any of the component metrics suggests the OIWI is more likely to indicate overall wetland condition rather than any particular stressor. And, the clear relationship of the OIWI to the buffer and landscape metrics supports the idea that adult odonates are also strong indicators of land use practices and integrity of the area surrounding the wetland breeding site.

Non-overlapping interquartile ranges suggest excellent capability of the OIWI to discriminate among reference categories, defined according to the RIRAM and ISA measures. Indeed, the entire OIWI distributions within RIRAM-designated leastdisturbed and most-disturbed wetlands were non-overlapping. Discriminating among disturbance classes is often a key objective of wetland assessment (Jacobs et al., 2010; U.S. EPA, 2006). The tighter relationship (better model fit) of the OIWI to the RIRAM than to ISA suggests that odonates as a group will respond more predictably to cumulative in-wetland and adjacent ( $<150 \mathrm{~m})$ stresses than to broader ( $300 \mathrm{~m})$ surrounding landscape stresses, even though the $\mathrm{CoC}$ were generated at the latter scale. This supports the fact that much adult odonate activity and abundance is localized in and around breeding habitat (Bried and Ervin, 2006; Butler and 
deMaynadier, 2008), and undermines the prevailing opinion that adult stages cannot indicate conditions at the breeding site (Raebel et al., 2010). Strong correlations between OIWI and RIRAM buffer metrics suggest that adult Odonata are highly sensitive to the condition of nearby uplands surrounding the breeding site. This contrasts with odonate larvae which may respond only or primarily to breeding site conditions (Raebel et al., 2012). We recommend a full evaluation of adults vs. larvae (or exuviae) based on concurrent sampling of both stages along the same disturbance gradient.

Simaika and Samways (2011) found that adult dragonfly species composition, as represented by the Dragonfly Biotic Index, was more efficient and effective than benthic macroinvertebrate composition for assessing river condition. Similar to the OIWI, their index incorporates aggregate sensitivity of adult odonates to human disturbances. Metrics evaluating geographical range and threat of extinction, typically associated with habitat conservation value, collectively outweigh the species sensitivity metric. But, it is unclear how these metrics affect the signal of human disturbance because they may correspond with conservatism, in that conservative species may be restricted in geographical range, or threatened, due to habitat degradation. The Odonata Habitat Index (Chovanec and Waringer, 2001), intended to assess the health of river-floodplain systems, incorporates metrics evaluating species abundance, niche width, and habitat preference. While niche width may correspond with conservatism, species abundance and habitat preferences are heavily weighted, shifting the index focus toward habitat suitability for Odonata and away from general ecological condition. In contrast to these methods, the OIWI uses only collective 
species sensitivity as the indicator, thereby inherently restricting the index assessment to site quality. Accordingly, any effective use of a wetland by adult Odonata was counted in generating the $\mathrm{CoC}$ and validating the OIWI. Although the OIWI performed well without separating resident (autochthonous, successfully emerged) and immigrant species, a validation analysis focused strictly on the resident assemblage may find an even better signal of site quality. This is because the in-wetland stress experienced during the larval period may carry over to determine the species present at the adult stage.

Our study indicates the potential value of adult Odonata species conservatism as an effective and efficient indicator of freshwater wetland condition. We propose that the OIWI may provide a reliable alternative or complement to the conservatismbased floristic quality indices that have become popular for wetland assessments in the United States (Bried et al., 2013; Cohen et al., 2004; Ervin et al., 2006; Lopez and Fennessey, 2002; Miller and Wardrop, 2006; Stein et al., 2009). The linear model fit between OIWI and measures of human disturbance was comparable to wetland assessments using floristic conservatism (e.g., Cohen et al., 2004; Ervin et al., 2006; Lopez and Fennessey, 2002; Miller and Wardrop, 2006). Because adult odonates require the habitat surrounding wetlands for maturation, foraging, nocturnal roosting, and other activities (Bried and Ervin, 2006 and references therein), and because the $\mathrm{CoC}$ are estimated objectively rather than using best professional judgment, the OIWI may provide a more integrated and accurate measure of wetland quality than siterestricted floristic assessments. A direct comparison of the OIWI and floristic quality methods is needed to test this prediction. Furthermore, the OIWI uses a readily 
observed insect group whose species identifications are easy to learn, and thus should not present any greater logistical difficulty than floristic-based assessments. However, we acknowledge that odonatists are outnumbered by botanists, and that odonates may not be present in all types of wetlands.

Similar to some floristic methods, OIWI is a straightforward, single-metric indicator of wetland condition that is easily understood and thus may be a more intuitive tool for practitioners than more complex indicators. The OIWI is based on the straightforward premise that because Odonata species exhibit differential tolerance to various human disturbances, species assemblage can reflect cumulative human disturbance at a given wetland. Assignment of $\mathrm{CoC}$ was also straightforward, based on the empirical analysis of species occurrences using observational data. Bioindicators that employ numerous metrics, complex metrics, or metrics based on a coarse or subjective characterization of condition (such as expert opinion) are more likely to contain biases and hidden information that cannot easily be understood and reconciled by the end user. Practitioners may therefore feel more confident applying the OIWI over more complex or subjective indicators.

\subsection{Methodology considerations}

We used the mean $\mathrm{CoC}$ for the OIWI and ignored species richness, which for odonates may correspond with site attributes other than ecological condition (Aliberti Lubertazzi and Ginsberg, 2010; Bried et al., 2007; Hornung and Rice, 2003; Sahlén and Ekestubbe, 2001). For example, several odonate studies have reported a positive relationship between number of species and patch area (Bried et al., 2012a; Kadoya et 
al., 2004; Samways et al., 2011). Additionally, the number of adult odonate species observed depends largely on the frequency and duration of surveys (Bried et al., 2012a; Simaika and Samways, 2009). Survey effort and assessment unit size varied greatly in the Rhode Island Odonata Atlas, but neither correlated with the OIWI, suggesting that these discrepancies did not affect OIWI values relative to our disturbance gradients; however, we hypothesize that patch area and sampling effort variability would confound the index if it incorporated species richness. Studies of floristic quality have also recognized the confounding influence of richness and recommended using mean CoC alone (Bried et al., 2013; Cohen et al., 2004; Miller and Wardrop, 2006; Rooney and Rogers, 2002).

A main goal of our study was to develop accurate Odonata $\mathrm{CoC}$ for practical application in wetland assessment. We therefore used three training groups, representing least-disturbed, intermediately-disturbed, and most-disturbed wetlands, to maximize $\mathrm{CoC}$ information under the data constraints of the Odonata Atlas. However, in applications collecting new Odonata training data or utilizing a more rigorous survey dataset, it may be more efficient and effective to use only least-disturbed and most-disturbed groups, at the expense of losing information from intermediatelydisturbed wetlands. Advantages could include a reduction in ecological noise, more efficient, targeted monitoring effort, and simpler $\mathrm{CoC}$ computations, using a single proportional value of affinity rather than averaging two (affinity to least-disturbed wetlands would automatically correspond to inverse affinity to most-disturbed wetlands). 
Our method of empirically assigning $\mathrm{CoC}$ could be applied to other large opportunistic or "citizen-science" datasets for Odonata, or to similar datasets for other species assemblages. For example, Micacchion (2004) used best professional judgment to assign coarse $\mathrm{CoC}$ to amphibian species to indicate the condition of seasonally-flooded ponds in Ohio, USA. Many states, including Ohio, have extensive spatially-referenced amphibian datasets that could be utilized for assessment by applying our methods to generate amphibian CoC. Similarly, Lussier et al. (2006) assigned subjective coefficients of tolerance to songbird guilds to help describe the ecological integrity of riparian corridors. Our methods could be applied to the extensive, existing songbird datasets to empirically assign $\mathrm{CoC}$ to individual bird species, which could potentially facilitate rapid assessment of large conservation areas using analysis of existing spatial data or new songbird point-counts. Also, floristic CoC could be validated or improved using similar methods (Bried et al., 2012b), although this could be an onerous task that would need to be weighed against potential benefits over expert-based CoC. Cohen et al. (2004) found negligible functional differences between index values using data-based versus opinion-based $\mathrm{CoC}$ for plants.

There are expected disadvantages to using odonate adults relative to larvae and exuviae. Flight activity is sensitive to weather conditions and may affect species' detection probability, generating noise in the data set. Also, presence of adults or their mating and oviposition attempts do not indicate successfully emerged or breeding resident species (Chovanec and Waringer, 2001; Raebel et al., 2010). Separating the 
resident and immigrant species may improve OIWI performance, but currently no criteria exist for doing so based only on adult surveys.

It is unclear whether species with low representation in the training sample were given accurate $\mathrm{CoC}$. Although the likelihood of any one or combination of these species strongly affecting OIWI outcomes across multiple wetlands is low, rare species may provide vital information for site-scale assessment (Poos and Jackson, 2012). Incorporating rare species allowed us to test the application of all available species information, which may be important for assessing wetlands with low species richness. Similarly, Simaika and Samways (2009) found that the Dragonfly Biotic Index was not substantially affected by occasional species, even as rarity (in terms of relative geographic distribution and conservation status) is heavily positively weighted in the index. In contrast, our empirical method of $\mathrm{CoC}$ allocation will favor rare species over common species only if they are primarily observed in undisturbed landscapes.

The number of species documented at certain study units may be biased low due to targeted sampling of early-season species during the Atlas (V. Brown, pers. comm.). In fact, the observed number of odonate species is likely biased low at any sites with one or few surveys. But if we assume this bias is evenly distributed (approximately) across the sample, then our novel approach to $\mathrm{CoC}$ designation can be applied using many large opportunistic data sets that already exist (e.g., White et al., 2010). A standardized sampling effort for adult Odonata over the flight season (see Bried et al., 2012a for guidance) at an independent set of wetlands could then be used to rigorously evaluate the performance of $\mathrm{CoC}$ estimated from opportunistic data. 


\subsection{Conclusion}

Many forms of wetland bioassessment exist with varying levels of complexity and required expertise (Rader et al., 2001; U.S. EPA, 2002). Our study demonstrates a straightforward and effective method of empirically assigning $\mathrm{CoC}$ to odonate species based on their affinity to disturbance classes assigned to a large opportunistic dataset. We found that adult Odonata sensitivity to disturbance, taken collectively across species, responds predictably to multiple aspects of wetland and adjacent buffer degradation, and declines monotonically in response to cumulative wetland degradation (i.e., general wetland condition) across a range of freshwater wetland types. These findings indicate the utility of adult Odonata as a meaningful and robust indicator of freshwater wetland condition. In addition to developing the $\mathrm{CoC}$ and testing the OIWI in other regions, future studies should compare the OIWI with the related floristic quality indices (Ervin et al., 2006; Taft et al., 2006), and with multimetric or multi-taxa indices (e.g., Brazner et al., 2007; Johnston et al., 2009) to evaluate how wetland assessments involving only adult odonates perform in relation to approaches requiring more taxa and expertise. 


\section{Acknowledgments}

We thank Carolyn Murphy, Graham Forrester, Rick McKinney, Q. Kellogg, and Peter Paton for providing technical advice. Ginger Brown provided comments on our methods and reviewed the Odonata coefficients of conservatism. David Gregg reviewed a draft of this manuscript. David Gregg, Susan Kiernan, and Carolyn Murphy administered this work and Deanna Levanti assisted with field work. Rhode Island Natural History Survey is housed by the University of Rhode Island, College of the Environment and Life Sciences. This project was funded by the Rhode Island Department of Environmental Management, Office of Water Resources, through a Wetlands Program Development Grant awarded by the United States Environmental Protection Agency. 


\section{References}

Aliberti-Lubertazzi, M.A., Ginsberg, H.S., 2010. Emerging dragonfly diversity at small Rhode Island (U.S.A.) wetlands along an urbanization gradient. Urban Ecosystems 13, 517-533.

Anderson, D.J., Vondracek, B., 1999. Insects as indicators of land use in three ecoregions in the prairie pothole region. Wetlands 19, 648-664.

Barbour, M.T., Gerritsen, J., Griffeth, G.E., Frydenborg, R., McCarron, E., White, J.S., Bastain, L., 1996. A framework for biological criteria for Florida streams using benthic macroinvertebrates. J. N. Am. Benthol. Soc. 15, 185-211.

Batzer, D.P., Rader, R.B., Wissinger, S.A. (Eds.), 1999. Invertebrates in Freshwater Wetlands of North America: Ecology and Management. John Wiley \& Sons, New York, USA.

Blois-Heulin, C., Crowley, P.H., Arrington, M., Johnson, D.M., 1990. Direct and indirect effects of predators on the dominant invertebrates of two freshwater littoral communities. Oecologia 84, 295-306.

Brazner, J.C., Danz, N.P., Niemi, G.J., Regal, R.R., Trebitz, A.S., Howe, R.W., Hanowski, J.M., Johnson, L.B., Ciborowski, J.J.H., Johnston, C.A., Reavie, E.D., Brady, V.J., Sgro, G.V., 2007. Evaluation of geographic, geomorphic, and human influences on Great Lakes wetland indicators: a multi-assemblage approach. Ecol. Indic. 7, 610-635.

Bried, J.T., Ervin, G.N., 2006. Abundance patterns of dragonflies along a wetland buffer. Wetlands 26, 878-833. 
Bried, J.T., Herman, B.D., Ervin, G.N., 2007. Umbrella potential of plants and dragonflies for wetland conservation: a quantitative case study using the umbrella index. J. Appl. Ecol. 44, 833-842.

Bried, J.T., Hager, B.J., Hunt, P.D., Fox, J.N., Jensen, H.J., Vowels, K.M., 2012a. Bias of reduced-effort community surveys for adult Odonata of lentic waters. Insect Conserv. Diver. 5, 213-222.

Bried, J.T., Strout, K.L., Portante, T., 2012b. Coefficients of conservatism for the vascular flora of New York and New England: inter-state comparisons and expert opinion bias. Northeast. Nat. 19(Special Issue 6), 101-114.

Bried, J.T., Jog, S.K., Matthews, J.W., 2013. Floristic quality assessment signals human disturbance over natural variability in a wetland system. Ecol. Indic. 34, 260-267.

Brinson, M.M., 1993. A hydrogeomorphic classification for wetlands. U.S. Army Corps of Engineers, Washington DC, Wetlands Research Program Technical Report.

Brown, V., Briggs, N., in prep. Rhode Island Odonata Atlas. Rhode Island Department of Environmental Management, Division of Fish and Wildlife, Providence, Rhode Island, USA.

Butler, R.G., deMaynadier, P.G., 2008. The significance of littoral and shoreline habitat integrity to the conservation of lacustrine damselflies (Odonata). J. Insect Conserv. 12, 23-36. 
Clark, T.E., Samways, M.J., 1996. Dragonflies (Odonata) as indicators of biotope quality in the Kruger National Park, South Africa. J. Appl. Ecol. 33, 10011012.

Chovanec, A., Schiemer, F., Waidbacher, H., Spolwind, R., 2002. Rehabilitation of a heavily modified river section of the Danube in Vienna (Austria): biological assessment of landscape linkages on different scales. Internat. Rev. Hydrobiol. 87(2-3), 183-195.

Chovanec, A., Waringer, J., 2001. Ecological integrity of river-floodplain systemsassessment by dragonfly surveys (Insecta: Odonata). Regul. Rivers: Res. Mgmt. 17, 493-507.

Cohen, M.J., Carstenn, S., Lane, C.R., 2004. Floristic quality indices for biotic assessment of depressional marsh condition in Florida. Ecol. Appl. 14, 784794.

Cowardin, L.M., Carter, V., Golet, F.C., LaRoe, E.T., 1979. Classification of wetlands and deepwater habitats of the United States. Office of Biological Services, Fish and Wildlife Service, U.S. Department of the Interior. Washington, DC

Cretini, K.F., Visser, J.M., Krauss, K.W., Steyer, G.D., 2012. Development and use of a floristic quality index for coastal Louisiana marshes. Environ. Monit. Assess. 184, 2389-2403.

Cummins, K.W., Merritt, R.W., 2001. Application of invertebrate functional groups to wetland ecosystem function and biomonitoring. In: Rader, R.B., Batzer, D.P., Wissinger, S.A. (Eds.), Bioassessment and Management of North American Freshwater Wetlands. John Wiley \& Sons, Inc., New York, USA, pp. 85-111. 
D’Amico, F., Darblade, S., Avignon, S., Blanc-Manel, S., Ormerod, S.J., 2004. Odonates as indicators of shallow lake restoration by liming: comparing adult and larval responses. Restor. Ecol. 12, 439-446.

Dolný, A., Harabiš, F., Bárta, D., Lhota, S., Drozd, P., (2012). Aquatic insects indicate terrestrial habitat degradation: changes in taxonomical structure and functional diversity of dragonflies in tropical rainforest of East Kalimantan. Trop. Zool. $25,141-157$.

Dufrene, M., Legendre, P., 1997. Species assemblages and indicator species: the need for a flexible asymmetrical approach. Ecol. Monogr. 67, 345-366.

Ervin, G.N., Herman, B.D., Bried, J.T., Holly, D.C., 2006. Evaluating non-native species and wetland indicator status as components of wetlands floristic assessment. Wetlands 26, 1114-1129.

Faber-Langendoen, D., Lyons, R., Comer, P., 2009. Developing options for establishing reference conditions for wetlands across the lower 48 states. NatureServe, Arlington, VA, USA.

Fennessy, M.S., Jacobs, A.D., Kentula, M.E., 2007. An evaluation of rapid methods for assessing the ecological condition of wetlands. Wetlands 27, 543-560.

Fleishman, E., Noss, R. F., Noon, B. R., 2006. Utility and limitations of species richness metrics for conservation planning. Ecol. Indic. 6, 543-553.

Flenner, I., Sahlén, G., 2008. Dragonfly community re-organization in boreal forest lakes: rapid species turnover driven by climate change? Insect Conserv. Divers. 1, 169-179. 
Foote, A.L., Hornung, C.L.R., 2005. Odonates as biological indicators of grazing effects on Canadian prairie wetlands. Ecol. Entomol. 30, 273-283.

Foster, S.E., Soluk, D.A., 2006. Protecting more than the wetland: the importance of biased sex ratios and habitat segregation for conservation of the Hine's emerald dragonfly, Somatochlora hineana Williamson. Biol. Conserv. 127, $158-166$.

Hilsenhoff, W.L., 1977. The use of arthropods to evaluate water quality of streams. Wisconsin Department of Natural Resources, Technical Bulletin No. 100.

Hornung, J.P., Rice, C.L., 2003. Odonata and wetland quality in southern Alberta, Canada: a preliminary study. Odonatologica 32, 119-129.

Jacobs, A.D., Kentula, M.E., Herlihy, A.T., 2010. Developing an index of condition from ecological data: an example using HGM functional variables from the Nanticoke watershed, USA. Ecol. Indic. 10, 703-712.

Johnston, C.A., Zedler, J.B., Tulbure, M.G., Frieswyk, C.B., Bedford, B.L., Vaccaro, L., 2009. A unifying approach for evaluating the condition of wetland plant communities and identifying related stressors. Ecol. Appl. 19, 1739-1757.

Kadoya, T., Suda, S., Washitani, I., 2004. Dragonfly species richness on man-made ponds: effects of pond size and pond age on newly established assemblages. Ecol. Res. 19, 461-467.

Karr, J.R., Chu, E.W., 1999. Restoring Life in Running Waters; Better Biological Monitoring. Island Press, Washington, DC. 
King, R.S., Richardson, C.J., 2002. Evaluating subsampling approaches and macroinvertebrate taxonomic resolution for wetland bioassessment. J. N. Am. Benthol. Soc. 21, 150-171.

Kutcher, T.E., 2011. Rhode Island rapid assessment method user's guide; RIRAM version 2.10. Rhode Island Department of Environmental Management, Office of Water Resources, Providence, Rhode Island, USA.

Lopez, R.D., Fennessy, M.S., 2002. Testing the floristic quality assessment index as an indicator of wetland condition. Ecol. Appl. 12, 487-497.

Lussier, S. M., Enser, R. W., Dasilva, S. N., Charpentier, M., 2006. Effects of habitat disturbance from residential development on breeding bird communities in riparian corridors. Environ. Manage., 38, 504-521.

Malmqvist, B, 2002. Aquatic invertebtrates in riverine landscapes. Freshw. Biol. 47, $679-694$.

Matthews, J.W., Tessene, P.A., Wiesbrook, S.M., Zercher, B.W., 2005. Effect of area and isolation on species richness and indices of floristic quality in Illinois, USA wetlands. Wetlands 25, 607-615.

Medley, L., Scozzafava, M., 2009. Moving toward a national floristic quality assessment: considerations for the EPA National Wetland Condition Assessment. Natl. Wetlands Newsl. 31(1), 6-9.

Micacchion, M., 2004. Integrated Wetland Assessment Program, Part 7: Amphibian Index of Biotic Integrity (AmphIBI) for Ohio Wetlands. Ohio EPA Technical Report WET/2004-7. Ohio Environmental Protection Agency, Wetland Ecology Group, Division of Surface Water, Columbus, Ohio, USA. 
Miller, S.J., Wardrop, D.H., 2006. Adapting the floristic quality assessment index to indicate anthropogenic disturbance in central Pennsylvania wetlands. Ecol. Indic. 6, 313-326.

Oertli, B. 2008. The use of dragonflies in the assessment and monitoring of aquatic habitats. Pages 79-95 in A. Córdoba-Aquilar (Ed.), Dragonflies and Damselflies: Model Organisms for Ecological and Evolutionary Research. Oxford University Press, Oxford, UK.

Poos, M.S., Jackson, D.A., 2012. Addressing the removal of rare species in multivariate bioassessments: the impact of methodological choices. Ecol. Indic. 18, 82-90.

Primack, R.B., Kobori, H., Mori, S., 2000. Dragonfly pond restoration promotes conservation awareness in Japan. Conserv. Biol. 14, 1553-1554.

Rader, R.B., Batzer, D.P., Wissinger, S.A. (Eds.), 2001. Bioassessment and Management of North American Freshwater Wetlands. John Wiley \& Sons, New York, USA.

Raebel, E.M., Merckx, T., Riordan, P., Macdonald, D.W., Thompson, D.J., 2010. The dragonfly delusion: why it is essential to sample exuviae to avoid biased surveys. J. Insect Conserv. 14, 523-534.

Raebel, E.M., Merckx, T., Feber, R.E., Riordan, P., Thompson, D.J., Macdonald, D.W., 2012. Multi-scale effects of farmland management on dragonfly and damselfly assemblages of farmland ponds. Agr. Ecosyst. Environ. 161, 80-87. 
Reece, B.A., McIntyre, N.E., 2009. Community assemblage patterns of odonates inhabiting a wetland complex influenced by anthropogenic disturbance. Insect Conserv. Diver. 2, 73-80.

Remsburg, A.J., Turner, M.G., 2009. Aquatic and terrestrial drivers of dragonfly (Odonata) assemblages within and among north-temperate lakes. J. N. Am. Benthol. Soc. 28, 44-56.

RIGIS, 2010. Rhode Island Geographic Information System Data. Available via http://www.edc.uri.edu/rigis/. Accessed 15 July 2010.

Robertson, M.P., Cumming, G.S., Erasmus, B.F.N., (2010) Getting the most out of atlas data. Divers. Distrib. 16, 363-375.

Rooney, T.P., Rogers, D.A., 2002. The modified floristic quality index. Nat. Areas J. $22,340-344$.

Rosset, V., Simaika, J. P., Arthaud, F., Bornette, G., Vallod, D., Samways, M. J., Oertli, B., 2013. Comparative assessment of scoring methods to evaluate the conservation value of pond and small lake biodiversity. Aquatic Conserv: Mar. and Freshw. Ecosyst. 23, 23-36.

Sahlén, G., Ekestubbe, K., 2001. Identification of dragonflies (Odonata) as indicators of general species richness in boreal forest lakes. Biodivers. Conserv. 10, 673690.

Samways, M.J. 2008. Dragonflies as focal organisms in contemporary conservation biology. Pages 97-108 in A. Córdoba-Aquilar (Ed.), Dragonflies and Damselflies: Model Organisms for Ecological and Evolutionary Research. Oxford University Press, Oxford, UK. 
Samways, M.J., Pryke, J.S., Simaika, J.P., 2011. Threats to dragonflies on land islands can be as great as those on oceanic islands. Biol. Conserv. 144, 1145-1151.

Sang, A., Teder, T., 2011. Dragonflies cause spatial and temporal heterogeneity in habitat quality for butterflies. Insect Conserv. Diver. 4, 257-264.

Sanzone, D. M., Meyer, J. L., Marti, E., Gardiner, E. P., Tank, J. L., Grimm, N. B., 2003. Carbon and nitrogen transfer from a desert stream to riparian predators. Oecologia, $134,238-250$.

Scozzafava, M., Kentula, M. E., Riley, E., Magee, T. K., Serenbetz, G., Sumner, R., Faulkner, C., Price, M., 2011. The National Wetland Condition Assessment: national data on wetland quality to inform and improve wetlands protection. National Wetlands Newsletter 33(2), 11-13.

Sifneos, J.C., Herlihy, A.T., Jacobs, A.D., Kentula, M.E., 2010. Calibration of the Delaware Rapid Assessment Protocol to a comprehensive measure of wetland condition. Wetlands 30, 1011-1022.

Silva, D., De Marco, P., Resende, D.C., 2010. Adult odonate abundance and community assemblage measures as indicators of stream ecological integrity: A case study. Ecol. Indic. 10, 744-752.

Simaika, J.P., Samways, M.J., 2009. An easy-to-use index of ecological integrity for prioritizing freshwater sites and for assessing habitat quality. Biodivers. Conserv. 18, 1171-1185.

Simaika, J.P., Samways, M.J., 2011. Comparative assessment of indices of freshwater habitat conditions using different invertebrate taxon sets. Ecol. Indic. 11, 370378. 
Stein, E.D., Fetscher, A.E., Clark, R.P., Wiskind, A., Grenier, J.L., Sutula, M., Collins, J.N., Grosso, C., 2009. Validation of a wetland rapid assessment method: use of EPA's level 1-2-3 framework for method testing and refinement. Wetlands 29, 648-665.

Swink, F., Wilhelm, G., 1979. Plants of the Chicago Region (revised and expanded edition with keys). The Morton Arboretum, Lisle, Illinois, USA.

Taft, J.B., Wilhelm, G.S., Ladd, D.M., Masters, L.A., 1997. Floristic quality assessment for vegetation in Illinois: a method for assessing vegetation integrity. Erigenia 15, 3-95.

Taft, J.B., Hauser, C., Robertson, K.R., 2006. Estimating floristic integrity in tallgrass prairie. Biol. Conserv. 131, 42-51.

Tangen, B.A., Butler, M.G., Ell, M.J., 2003. Weak correspondence between macroinvertebrate assemblages and land use in Prairie Pothole Region wetlands, USA. Wetlands 23, 104-115.

Turner, A.M., Trexler, J.C., 1997. Sampling aquatic invertebrates from marshes: evaluating the options. J. N. Am. Benthol. Soc. 16, 694-709.

U.S. EPA, 2002. Methods for evaluating wetland condition: Developing metrics and indexes of biological integrity. Office of Water, U.S. Environmental Protection Agency, Washington, DC. EPA 822-R-02-016.

U.S. EPA, 2006. Application of elements of a state water monitoring and assessment program for wetlands. Wetlands Division, Office of Wetlands, Oceans and Watersheds, U.S. Environmental Protection Agency, Washington, DC. 
Veselka, W., Anderson, J.T., Kordek, W.S., 2010. Using dual classifications in the development of avian wetland indices of biological integrity for wetlands in West Virginia, USA. Environ. Monit. Assess. 164, 533-548.

White, E.L., Corser, J.D., Schlesinger, M.D., 2010. The New York Dragonfly and Damselfly Survey, 2005-2009: Distribution and Status of the Odonates of New York. New York Natural Heritage Program, Albany, New York USA. Available via http://www.dec.ny.gov/animals/31061.html. Accessed 29 December 2011

Wissinger, S.A., 1999. Ecology of wetland invertebrates: synthesis and applications for conservation and management. In: Batzer, D.P., Rader, R.B., Wissinger, S.A., (Eds.), Invertebrates in Freshwater Wetlands of North America: Ecology and Management. John Wiley \& Sons, New York, USA. pp. 1043-1086.

Wittwer, T., Sahlén, G., Suhling, F., 2010. Does one community shape the other? Dragonflies and fish in Swedish lakes. Insect Conserv. Diver. 3, 124-133. 
Table 1. Components of the Rhode Island Rapid Assessment Method for evaluating freshwater wetland condition

\section{Metric}

1. Integrity of Buffers

2. Integrity of Surrounding Landscape

3. Impoundment

4. Draining or Diversion of Water

5. Anthropogenic Fluvial Inputs

6. Filling and Dumping

7. Excavation and Substrate Disturbances

8. Vegetation and Detritus Removal

9. Invasive Species within Wetland

10. Observed State

\section{Metric Scoring Criteria}

Estimates \% cultural cover class within 100ft (30m) of unit

Generates a weighted average of four land-use-intensity categories by relative proportion within $500 \mathrm{ft}(150 \mathrm{~m})$ of unit

Estimates water regime change and proportion of unit affected, and identifies barriers to resource movement

Estimates water regime change and proportion of the unit affected

Estimates impacts of four types of fluvial inputs including nutrients, sediments and solids, toxins and salts, and flashiness

Estimates the intensity of fill within or abutting the wetland and the proportion of the unit affected

Estimates the intensity of substrate disturbances within the wetland and the proportion of the unit affected

Estimates the extent and the proportion of vegetation and detritus removal from each of five vegetation strata

Estimates the collective cover class of all identified invasive plant species

Rates the apparent integrity of five wetland functional characteristics, including hydrologic integrity, water and soil quality, habitat structure, vegetation composition, and habitat connectivity 
Table 2. Coefficients of conservatism $(\mathrm{CoC})$ for 135 Odonata species known to occur

in Rhode Island and the number of training sites where each was collected; $L D=$ least-

disturbed, $I D=$ intermediately-disturbed, and $M D=$ most-disturbed

\begin{tabular}{|c|c|c|c|c|c|c|c|c|c|c|c|}
\hline \multirow[b]{2}{*}{ Species } & \multirow[b]{2}{*}{$\mathrm{CoC}$} & \multicolumn{4}{|c|}{ Training Sites } & \multirow[b]{2}{*}{ Species } & \multirow[b]{2}{*}{$\mathrm{CoC}$} & \multicolumn{4}{|c|}{ Training Sites } \\
\hline & & $L D$ & $I D$ & $M D$ & Total & & & $L D$ & $I D$ & $M D$ & Total \\
\hline Aeshna clepsydra & 8.3 & 16 & 3 & 2 & 21 & Helocordulia uhleri & 7.7 & 9 & 5 & 1 & 15 \\
\hline Aeshna tuberculifera & 8.2 & 12 & 7 & 0 & 19 & Ischnura kellicotti & 5.2 & 8 & 8 & 7 & 23 \\
\hline Aeshna umbrosa & 6.2 & 11 & 9 & 5 & 25 & Ischnura posita & 4.1 & 29 & 36 & 51 & 116 \\
\hline Aeshna verticalis & 8.6 & 14 & 3 & 1 & 18 & Ischnura ramburii & 0.0 & 0 & 0 & 4 & 4 \\
\hline Anax longipes & 8.3 & 5 & 0 & 1 & 6 & Lestes congener & 5.7 & 10 & 6 & 7 & 23 \\
\hline Argia apicalis & 1.9 & 0 & 3 & 5 & 8 & Lestes disjunctus & 6.7 & 18 & 15 & 5 & 38 \\
\hline Argia fumipennis & 4.6 & 23 & 31 & 29 & 83 & Lestes dryas & 3.3 & 0 & 2 & 1 & 3 \\
\hline Argia moesta & 2.6 & 2 & 6 & 11 & 19 & Lestes eurinus & 8.0 & 11 & 2 & 2 & 15 \\
\hline Argia translata & 2.0 & 0 & 2 & 3 & 5 & Lestes forcipatus & 5.9 & 21 & 21 & 11 & 53 \\
\hline Arigomphus furcifer & 6.7 & 5 & 2 & 2 & 9 & Lestes inaequalis & 5.8 & 17 & 16 & 10 & 43 \\
\hline Calopteryx maculata & 5.7 & 31 & 33 & 20 & 84 & Leucorrhinia hudsonica & 7.8 & 6 & 2 & 1 & 9 \\
\hline Celithemis elisa & 5.7 & 22 & 18 & 14 & 54 & Leucorrhinia intacta & 6.3 & 20 & 19 & 8 & 47 \\
\hline Celithemis eponina & 4.6 & 6 & 9 & 8 & 23 & Leucorrhinia proxima & 8.8 & 3 & 1 & 0 & 4 \\
\hline Celithemis fasciata & 7.7 & 9 & 5 & 1 & 15 & Libellula auripennis & 10.0 & 0 & 0 & 0 & 0 \\
\hline Celithemis martha & 6.5 & 10 & 2 & 5 & 17 & Libellula axilena & 8.8 & 3 & 1 & 0 & 4 \\
\hline Chromagrion conditum & 6.7 & 31 & 21 & 10 & 62 & Libellula cyanea & 6.4 & 20 & 15 & 8 & 43 \\
\hline Cordulegaster diastatops & 8.5 & 9 & 4 & 0 & 13 & Libellula deplanata & 8.3 & 2 & 1 & 0 & 3 \\
\hline Cordulegaster maculata & 7.5 & 7 & 4 & 1 & 12 & Libellula exusta & 8.1 & 27 & 9 & 3 & 39 \\
\hline Cordulegaster obliqua & 10.0 & 2 & 0 & 0 & 2 & Libellula incesta & 5.4 & 29 & 28 & 22 & 79 \\
\hline Cordulia shurtleffi & 8.3 & 2 & 1 & 0 & 3 & Libellula julia & 10.0 & 5 & 0 & 0 & 5 \\
\hline Didymops transversa & 7.5 & 6 & 6 & 0 & 12 & Libellula luctuosa & 4.0 & 10 & 26 & 22 & 58 \\
\hline Dorocordulia lepida & 8.8 & 22 & 5 & 1 & 28 & Libellula lydia & 6.0 & 26 & 19 & 14 & 59 \\
\hline Dorocordulia libera & 10.0 & 6 & 0 & 0 & 6 & Libellula needhami & 1.0 & 0 & 1 & 4 & 5 \\
\hline Enallagma durum & 1.3 & 0 & 1 & 3 & 4 & Nehalennia integricollis & 10.0 & 1 & 0 & 0 & 1 \\
\hline Enallagma ebrium & 5.7 & 4 & 8 & 2 & 14 & Nehalennia irene & 6.0 & 9 & 11 & 4 & 24 \\
\hline Enallagma exsulans & 2.1 & 1 & 7 & 13 & 21 & Neurocordulia obsoleta & 7.5 & 1 & 1 & 0 & 2 \\
\hline Enallagma geminatum & 4.7 & 28 & 30 & 33 & 91 & Ophiogomphus aspersus & 9.4 & 7 & 1 & 0 & 8 \\
\hline Enallagma hageni & 6.5 & 5 & 3 & 2 & 10 & Ophiogomphus mainensis & 8.8 & 3 & 1 & 0 & 4 \\
\hline Enallagma laterale & 6.4 & 14 & 8 & 6 & 28 & Pachydiplax longipennis & 4.1 & 21 & 22 & 36 & 79 \\
\hline Enallagma minusculum & 6.1 & 3 & 5 & 1 & 9 & Pantala flavescens & 3.1 & 2 & 4 & 7 & 13 \\
\hline Enallagma pictum & 7.5 & 7 & 1 & 2 & 10 & Pantala hymenaea & 2.3 & 0 & 5 & 6 & 11 \\
\hline Enallagma recurvatum & 8.2 & 10 & 3 & 1 & 14 & Perithemis tenera & 3.9 & 11 & 19 & 23 & 53 \\
\hline Enallagma signatum & 3.7 & 9 & 25 & 24 & 58 & Progomphus obscurus & 8.8 & 3 & 1 & 0 & 4 \\
\hline Enallagma traviatum & 4.3 & 4 & 12 & 7 & 23 & Somatochlora georgiana & 9.0 & 4 & 1 & 0 & 5 \\
\hline Enallagma vesperum & 4.5 & 4 & 9 & 6 & 19 & Somatochlora linearis & 8.8 & 10 & 3 & 0 & 13 \\
\hline Enallagma weewa & 7.1 & 5 & 0 & 2 & 7 & Somatochlora tenebrosa & 8.8 & 24 & 8 & 0 & 32 \\
\hline Epiaeschna heros & 6.7 & 5 & 2 & 2 & 9 & Somatochlora walshii & 9.0 & 4 & 1 & 0 & 5 \\
\hline Epitheca canis & 8.8 & 3 & 1 & 0 & 4 & Somatochlora williamsoni & 10.0 & 3 & 0 & 0 & 3 \\
\hline Epitheca cynosura & 6.3 & 32 & 31 & 12 & 75 & Stylogomphus albistylus & 6.4 & 8 & 7 & 3 & 18 \\
\hline Epitheca princeps & 5.8 & 7 & 7 & 4 & 18 & Stylurus scudderi & 6.7 & 1 & 2 & 0 & 3 \\
\hline Epitheca spinigera & 8.8 & 3 & 1 & 0 & 4 & Stylurus spiniceps & 5.0 & 0 & 2 & 0 & 2 \\
\hline Erythemis simplicicollis & 5.3 & 20 & 23 & 16 & 59 & Sympetrum costiferum & 4.5 & 4 & 2 & 5 & 11 \\
\hline Erythrodiplax berenice & 3.7 & 5 & 7 & 11 & 23 & Sympetrum internum & 5.0 & 34 & 34 & 34 & 102 \\
\hline Gomphaeschna antilope & 7.5 & 1 & 1 & 0 & 2 & Sympetrum rubicundulum & 4.2 & 2 & 6 & 4 & 12 \\
\hline Gomphaeschna furcillata & 8.5 & 16 & 7 & 0 & 23 & Sympetrum semicinctum & 7.0 & 13 & 9 & 3 & 25 \\
\hline Gomphus abbreviatus & 5.0 & 1 & 2 & 1 & 4 & Sympetrum vicinum & 5.6 & 21 & 16 & 15 & 52 \\
\hline Gomphus adelphus & 8.0 & 3 & 2 & 0 & 5 & Tramea carolina & 5.3 & 7 & 2 & 6 & 15 \\
\hline Gomphus exilis & 7.1 & 34 & 28 & 6 & 68 & Tramea lacerata & 5.0 & 8 & 8 & 8 & 24 \\
\hline Gomphus lividus & 7.8 & 6 & 2 & 1 & 9 & Williamsonia lintneri & 7.5 & 3 & 3 & 0 & 6 \\
\hline
\end{tabular}


Table 3. Odonata Index of Wetland Integrity (OIWI) values and effort data from 51 wetland assessment units in Rhode Island; information is listed in decreasing order of OIWI

\begin{tabular}{|c|c|c|c|c|}
\hline Wetland Unit & OIWI & \# Visits & \# Specimens & \# Species \\
\hline SMA-ARC-BFFEN & 7.16 & 8 & 26 & 17 \\
\hline SMA-ARC-WD3 & 7.06 & 11 & 24 & 14 \\
\hline AUD-EPP-QR4 & 6.82 & 5 & 11 & 6 \\
\hline SMA-CAR-WLPD & 6.79 & 9 & 34 & 11 \\
\hline PRV-BOTH-PND & 6.78 & 7 & 124 & 47 \\
\hline AUD-FISH-BRK & 6.77 & 5 & 14 & 10 \\
\hline TNC-XXX-QR2 & 6.74 & 30 & 69 & 37 \\
\hline PRV-MAIL-FEN & 6.72 & 3 & 10 & 5 \\
\hline SMA-ARC-RBPD & 6.72 & 5 & 62 & 29 \\
\hline PRV-GRSY-PND & 6.69 & 8 & 19 & 7 \\
\hline SMA-BIG-CAP & 6.64 & 18 & 105 & 43 \\
\hline TNC-ELL-PND & 6.64 & 3 & 14 & 8 \\
\hline SMA-DUR-TEPE & 6.53 & 5 & 55 & 29 \\
\hline PRV-PED-PND & 6.46 & 4 & 28 & 14 \\
\hline PRV-MOW-BRK2 & 6.45 & 5 & 13 & 9 \\
\hline PRV-HART-BOG & 6.40 & 4 & 50 & 24 \\
\hline SMA-GSW-CHIP7 & 6.36 & 3 & 18 & 11 \\
\hline PRV-SNAKE-POW & 6.34 & 5 & 16 & 8 \\
\hline PRV-JACK-SCPD & 6.29 & 3 & 15 & 15 \\
\hline SMA-CAR-FISH & 6.29 & 16 & 37 & 18 \\
\hline PRV-R216-POW & 6.28 & 5 & 16 & 13 \\
\hline PRV-PYSZ-FEN & 6.26 & 10 & 34 & 19 \\
\hline AUD-CARD-SWP & 6.24 & 5 & 41 & 23 \\
\hline SMA-WOO-IMP & 6.24 & 17 & 99 & 34 \\
\hline PRV-GLAC-PND & 6.16 & 8 & 54 & 22 \\
\hline PRV-FORG-GRN1 & 6.10 & 18 & 55 & 23 \\
\hline PRV-BRCH-STA1 & 6.01 & 6 & 64 & 36 \\
\hline SMA-ARC-MOON & 5.93 & 7 & 13 & 8 \\
\hline SMA-GWMA-OKPD & 5.92 & 7 & 32 & 19 \\
\hline SMA-BUCK-PD1 & 5.88 & 6 & 34 & 21 \\
\hline TNC-CRTR-WET1 & 5.83 & 4 & 17 & 4 \\
\hline AUD-NEW-PND & 5.82 & 4 & 53 & 24 \\
\hline PRV-XXX-PWT5 & 5.65 & 6 & 26 & 15 \\
\hline PRV-SLTR-PRK0 & 5.49 & 5 & 16 & 11 \\
\hline PRV-HUNT-STA3 & 5.37 & 5 & 57 & 21 \\
\hline PRV-BUTT-PND & 5.32 & 4 & 20 & 12 \\
\hline PRV-THIR-PND & 5.27 & 4 & 10 & 9 \\
\hline PRV-TEN-RIV1 & 5.17 & 10 & 36 & 19 \\
\hline PRV-WOON-STA3 & 5.14 & 10 & 34 & 16 \\
\hline PRV-CARR-PND & 5.13 & 5 & 19 & 9 \\
\hline PRV-LONS-MRSH & 5.13 & 5 & 15 & 10 \\
\hline PRV-EVAN-PND & 5.11 & 4 & 17 & 12 \\
\hline PRV-ASHA-RIV2 & 5.04 & 6 & 17 & 13 \\
\hline PRV-XXX-PWT17 & 5.03 & 4 & 15 & 12 \\
\hline PRV-WAR-RES & 4.95 & 14 & 43 & 21 \\
\hline PRV-WOON-STA4 & 4.95 & 4 & 22 & 11 \\
\hline PRV-BLRD-PARK & 4.94 & 8 & 22 & 9 \\
\hline PRV-MITC-PND & 4.85 & 3 & 25 & 13 \\
\hline PRV-MOSH-PND & 4.78 & 10 & 55 & 17 \\
\hline PRV-NOTT-PD1 & 4.50 & 4 & 16 & 11 \\
\hline PRV-DMCR-PLAY & 3.74 & 4 & 11 & 5 \\
\hline
\end{tabular}


Table 4. Confidence limits $\left(2.5^{\text {th }}\right.$ and $97.5^{\text {th }}$ percentiles $)$ of linear model fit between individual RIRAM metrics (see Table 1) and the OIWI based on computer-intensive resampling (1,000 iterations); metrics 1, 2 and 10 decreased with increased disturbance whereas metrics 4 through 9 increased

\begin{tabular}{lcc}
\hline Metric & Low $\mathbf{R}^{\mathbf{2}}$ & High $\mathbf{R}^{\mathbf{2}}$ \\
\hline 1. Integrity of Buffers & 0.579 & 0.787 \\
2. Integrity of Surrounding Landscape & 0.507 & 0.793 \\
3. Impoundment & 0.000 & 0.121 \\
4. Draining or Diversion of Water & 0.128 & 0.502 \\
5. Anthropogenic Fluvial Inputs & 0.212 & 0.650 \\
6. Filling and Dumping & 0.314 & 0.610 \\
7. Excavation and Substrate Disturbances & 0.013 & 0.245 \\
8. Vegetation and Detritus Removal & 0.001 & 0.238 \\
9. Invasive Species within Wetland & 0.183 & 0.545 \\
10. Observed State & 0.539 & 0.792 \\
\hline
\end{tabular}


Fig. 1
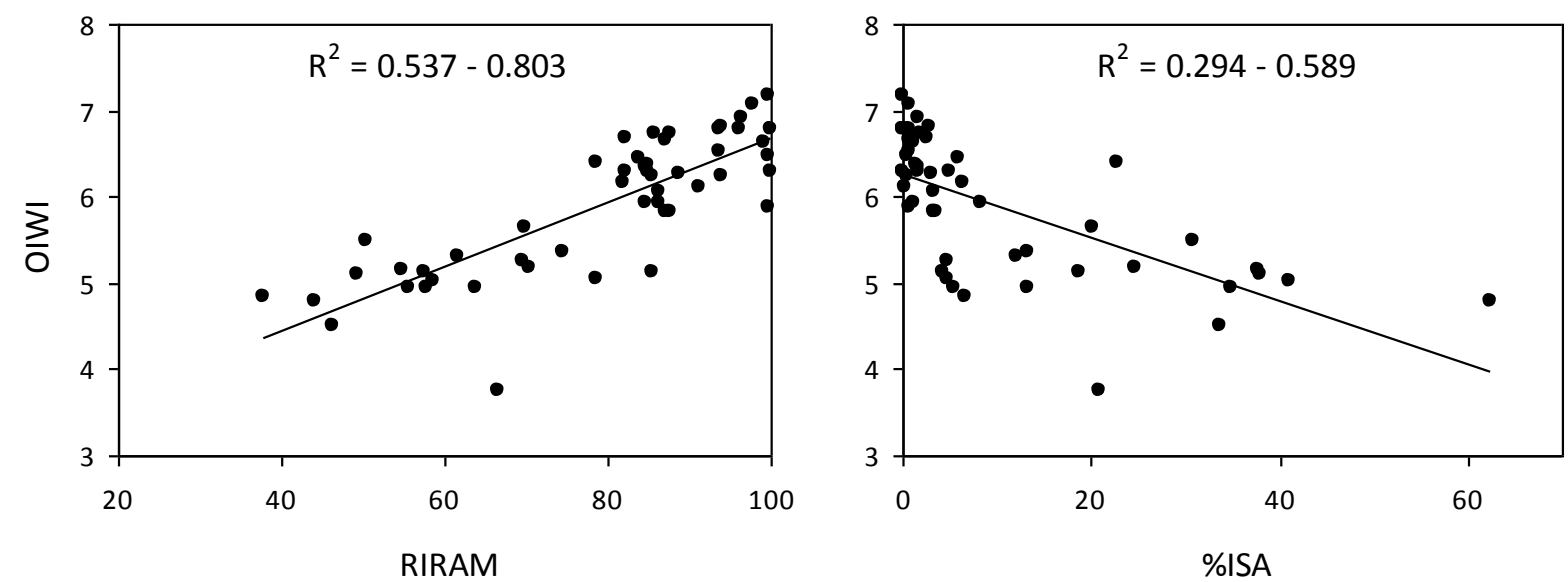

Fig. 1 Performance of the OIWI: Odonata Index of Wetland Integrity for 51 wetland sites in relation to the Rhode Island Rapid Assessment Method and \% impervious surface area (measured in a 305-m buffer around each site); model fit $\left(\mathrm{R}^{2}\right)$ is based on computer-intensive resampling with 1,000 iterations; best fit line is based on linear regression 
Fig. 2
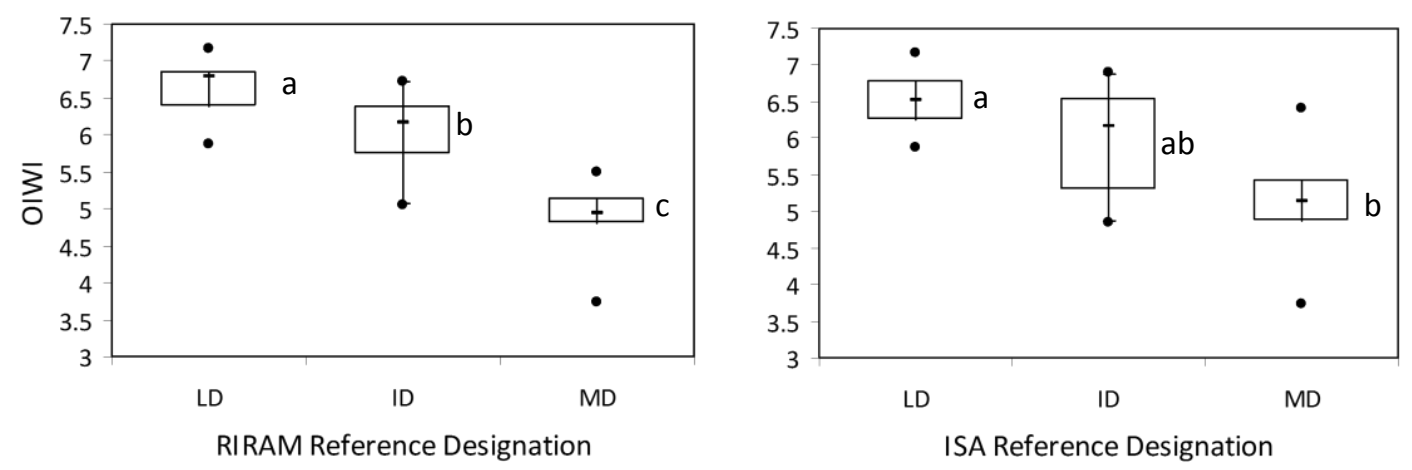

Fig. 2 Discriminating among disturbance designations: Box and whisker plots depicting the distribution of OIWI values $(n=51)$ in relation to three reference designations derived from RIRAM and ISA values, respectively; LD = least-disturbed, ID = intermediately-disturbed, and MD = most-disturbed. The center dash represents the median $(a>b>c)$, the box represents the interquartile range, the whiskers represent $2.5^{\text {th }}$ and $97.5^{\text {th }}$ percentiles, and the round symbols represent maximum and minimum values 


\section{CHAPTER 2}

Formatted in the style of Ecological Applications

Ecological mechanisms driving floristic quality assessment of wetland integrity

Thomas E. Kutcher ${ }^{1,2 *}$ and Graham E. Forrester ${ }^{2}$

${ }^{1}$ Rhode Island Natural History Survey, University of Rhode Island, Kingston, RI, 02881

${ }^{2}$ Department of Natural Resources Science, University of Rhode Island, Kingston, RI, 02881

*Email: tomkutcher@my.uri.edu 


\begin{abstract}
A biological indicator should be validated before it is used, but empirical validation against a reference measure may introduce bias. Focusing on the assumptions and mechanisms of indicator response rather than on increasing responsiveness to any one measure can reduce bias and produce a more meaningful and useful metric. Floristic Quality Assessment (FQA) is an example of a biological assessment approach that has been widely tested for indicating freshwater wetland integrity, but less attention has been given to clarifying the mechanisms controlling its response. FQA indices quantify the aggregate of vascular plant species intolerance to habitat degradation (conservatism), and variants have incorporated species richness, abundance, and nativeness. To assess bias, we tested FQA variants in open-canopy freshwater wetlands against three independent reference measures. FQA variants incorporating species richness did not correlate with our reference measures and were influenced by wetland size and hydrogeomorphic class. In contrast, FQA variants lacking measures of species richness responded linearly to reference measures quantifying individual and aggregate stresses, suggesting a broad response to cumulative degradation. FQA variants incorporating non-native species improved performance over using only native species, and incorporating relative species abundance improved performance further. Our findings support recognized ecological theories that help clarify the mechanisms and implications of FQA; specifically, aggregate conservatism declines with increased disturbance; species richness increases with intermediate disturbance and with unit area, confounding FQA response; non-native species are favored by human disturbance, and are thus relevant to FQA; and proportional abundance of
\end{abstract}


species provides important information on community composition, bolstering FQA relevance at the site level. Considering these mechanisms and their implications allowed us to identify the most relevant and effective FQA measure of ecological integrity for vegetated wetlands. We recommend an abundance-weighted FQA variant incorporating non-native species and disregarding species richness for the assessment of open-canopy vegetated wetlands.

\section{Keywords}

Biological indicator; ecological integrity; non-native species; intermediate disturbance hypothesis; species richness; vascular plant; wetland assessment. 


\section{Introduction}

Biological indicators (or bioindicators) are desirable for ecological assessment because they can provide objective, reliable, and precise measures of environmental condition (U.S. EPA 2006; Sifneos et al. 2010). Bioindicators can act as continuous, integrative in-situ ecosystem monitors that may react predictably to multiple, cumulative or synergistic environmental factors, and detect episodic events that periodic physical or chemical monitoring may not capture (Barbour et al. 1996). Bioindicators range in complexity from single indicator species to multivariate and multi-metric indices based on multiple attributes of multiple taxa. Multivariate and multi-metric indicators are attractive to practitioners interested in assessing ecological integrity because they are more likely to capture overall ecosystem response to environmental conditions (Karr 1991; Birk et al. 2012). The complexity of these indicators may also, however, be a drawback if the component metrics show interactive or countervailing responses that make the final indicator difficult to interpret (Karr and Chu 1999).

To ensure its effectiveness in reflecting environmental conditions, a bioindicator can be validated by assessing its response to degradation against a reference measure of condition (U.S. EPA 2002). The conclusiveness of such empirical validation, however, depends on the reference measure accurately reflecting the targeted ecological condition; and on the reference study sample spanning the full range of conditions in the habitat of interest (Karr 2006). But, due to the complexities and variability of the natural world, such impeccable standards are unlikely to exist (Cairns et al. 1993). The common practice of aggregating and calibrating attributes to 
improve indicator response to a reference standard increases the risk of introducing further bias due to circularity among the metrics.

Practitioners may be better served by focusing more on the implications of indicator response to various reference measures, rather than on increasing responsiveness to any one measure. Interpretation of response is central to indicator utility and relies on a clear understanding of the underlying ecological mechanisms driving response (Dale and Beyeler 2001; U.S. EPA 2002), but this is often overlooked (Niemi and McDonald 2004; Birk et al. 2012). Floristic Quality Assessment (FQA) is an example of a biological assessment approach that has been widely tested, yet remains poorly understood because some of the underlying mechanisms driving its functionality have not been clarified.

FQA is a biological assessment approach based on vascular plant species conservatism (intolerance to habitat degradation). FQA applies "coefficients of conservatism" (CC), ranging from 0 to 10 , to rank the perceived intolerance of individual plant species to habitat degradation caused by human disturbances. Regional CC are typically assigned to species through the consensus of a panel of expert botanists employing best professional judgment. Higher CC are assigned to plants with narrower environmental tolerances and higher sensitivity to disturbance; lower CC are assigned to species with broad tolerance to disturbance. FQA theory holds that aggregate $\mathrm{CC}$ of all vascular plants occupying a natural area can reflect environmental quality by quantifying the relative prevalence of conservative versus tolerant species. Although FQA was originally developed as a means of applying existing plant inventory data to indicate the conservation value of broad conservation 
areas (Swink and Wilhelm 1979), recent work has demonstrated its efficacy in the assessment of freshwater wetland integrity and restoration success using targeted vegetation sampling (Lopez and Fennessey 2002, Cohen et el. 2004, Miller and Wardrop 2006, Matthews et al. 2009; Bried et al. 2013).

The formula describing the original Floristic Quality Assessment Index (FQAI) used only native species and is comprised of conservatism and species richness (Swink and Wilhelm 1979). Specifically, FQAI weights the mean CC of native species $\left(\right.$ Mean $C C_{n}$ ) by the square root of the number of native species observed per site (a proxy for native species richness) (Table 1). This original formula has attracted the interest of freshwater wetland managers because it is based on plant species composition, which is a keystone functional component of vegetated wetlands (Mitsch and Gosselink 2000), and as such, is closely linked to wetlands management. Additionally, FQAI is intuitively meaningful, combining measures of tolerance and diversity, and can be derived using basic plant inventory methods (e.g. Lopez and Fennessey 2002, Bourdaghs et al. 2006). As it has been tested and applied, however, several studies have suggested that certain components and variants of the original formula may better predict wetland integrity.

Rooney and Rogers (2002) report that $M e a n C C_{n}$ alone may be a better measure of ecological condition, since it does not incorporate species richness and thus is not sensitive to sample size, preserves the information inherent in the $\mathrm{CC}$, and generates a more logical and understandable result. A Mean $C C$ variant including nonnative species (Mean $C C_{s}$, where $s$ indicates total species), a variant weighting Mean $C C_{n}$ by species abundance (Weighted mean $C C_{n}$ ), and a weighted variant 
incorporating non-native species (Weighted mean $C C_{s}$ ) have been considered for wetland assessment (Cohen et al. 2004; Bourdaghs et al. 2006; Bried et al. 2013). In these variants, non-native species are typically assigned a $\mathrm{CC}$ of 0 , regardless of their actual conservatism. Miller and Wardrop (2006) demonstrated the effectiveness of FQA expressed as the proportion of "maximum-attainable $F Q A \Gamma^{\prime}$ ( $F Q A I$ '), which discounts species richness and incorporates non-native species, whereas Matthews et al. (2009) demonstrated a version of the original FQAI incorporating both non-native species and richness $\left(F Q A I_{t}\right)$. Ervin et al. (2006) found that simply \% Native, discounting both richness and conservatism, outperformed FQAI.

As FQA gains recognition as an indicator of freshwater wetland condition, there is a growing need to clarify the implications of selecting different FQA variants for practitioners. While several variants of the original FQA metric have been empirically validated, less attention has been given to comparing their ecological and functional interpretation. Consequently, there has been considerable disagreement among researchers in identifying the most effective and meaningful FQA metrics for wetland assessment. In this paper, we empirically test several FQA variants from the literature against independently-derived landscape, rapid, and biological reference measures. By using three separate reference measures, we assess the robustness of empirical validation to bias in reference measures. We apply data-collection methods designed to be practical and effective for state and tribal assessment protocols, and analyze how the FQA variants respond to practical reductions in sampling effort. We then relate our empirical findings to ecological theory to clarify the validation results and interpret the relative performance of the FQA variants. This information should 
help practitioners to better plan assessments, interpret assessment findings, and manage wetland resources.

\section{Methods}

Study Sample

Our study was conducted in Rhode Island, USA. Our study sample comprised 20 freshwater wetland sites selected from a larger set of 51 sites that had been previously assessed using landscape, rapid, and biological assessment measures (Kutcher and Bried 2014). These sites were generally open-canopy vegetated wetlands with low tree cover $(<50 \%)$ and substantial occurrence of emergent vegetation $(>25 \%$ cover). Study sites were selected to span a range of wetland conditions (according to measures applied in Kutcher and Bried 2014) and types, and were spread geographically across Rhode Island. The site boundaries were delineated by basin continuity, bound by any combination of upland, riverine open water, or lacustrine open water, large roads or railways lacking culverts, or changes in hydrogeomorphology. The sites were not divided by vegetation type, thus a single site could contain multiple vegetation community types.

\section{Vegetation Sampling for FQA}

To address the assumptions of FQA methodology, while considering metric operability and user practicality, our vegetation sampling aimed to efficiently produce a nearly-complete list of vascular plant species per site and estimate the relative cover of each species. We also sought to standardize sampling effort according to site area. Vegetation data were collected along three 4-m wide belt transects, the first running 
centrally along the longest dimension of the site, and the remaining two running perpendicular to the first at one-third and two-thirds the distance from the start of the first transect. For riverine wetlands that were sinuous and narrow, the first transect was composed of the fewest connected straight lines needed to approximately follow the contours of the site. Transects were hand-drawn on aerial photographs prior to site visits, and landmarks visible on the maps (such as evergreen trees, rocks, roads) were used to navigate in the field. Transects were walked and, when necessary, canoed. Every vascular plant observed was identified to species and recorded onto field datasheets. Plants that could not be identified in the field were tagged and placed in plastic bags for laboratory identification. The few immature samples that could not be identified in the field or laboratory were not included in our analysis.

Following each transect, the abundance of each species was recoded as one of three classes: rank $1=$ scarce $(<10 \%$ cover $)$, rank $2=$ common $(10-60 \%$ cover $)$, and rank 3 = dominant $(>60 \%$ cover $)$. Site-wide mean ranks were used as replicates for data analyses. Incidental observations of species observed outside the transects were added to species totals and assigned a site-wide abundance rank of 1.

\section{Generating FQA Indices}

We assessed six FQA indices taken directly from prior studies, or developed based on a logical extension of published, empirically-tested formulas (Table 1). Values for each FQA index were calculated for each of our 20 study sites using recent Rhode Island-specific plant CC. The CC of all vascular plant species known to exist in Rhode Island were assigned by expert opinion of a regional expert botanist, according to methods detailed in Bried et al. (2012). The CC were based mainly on each species' 
relative sensitivity to human disturbances and, to a lesser degree, on niche width ( $R$. Enser, personal communication). Non-native species (not native to Rhode Island) were assigned a CC of zero. In total, 1558 species were assigned CC ranging in value from 0 to 10 with a mean of $3.7 \pm 2.9$ and a median of 3 ; non-native species comprised $28 \%$ of these species. For the FQA indices that use species abundance, calculations were made using midpoints of cover class ranges, where Rank $1=5 \%$ cover, Rank $2=35 \%$ cover, and Rank $3=80 \%$ cover.

Three reference measures of wetland condition

Impervious Surface Area. Impervious surface area (ISA) values were generated for each site as a landscape-level reference measure of wetland disturbance. Using ESRI ArcMap® ${ }^{\circledR} .3$ GIS software, 305-m surrounding-area polygons were generated for each site using the "buffer" command and selecting "outside only". Resulting surrounding-area polygons were used to clip recent high-resolution impervious surface raster data. Resulting impervious surrounding-area raster data were then coded and analyzed to determine the proportion of impervious cover surrounding each site; this was used as the ISA value.

Rhode Island Rapid Assessment Method. Rhode Island Rapid Assessment Method (RIRAM) data were collected according to the RIRAM User's Guide (Kutcher, 2010). RIRAM is an evidence-based rapid assessment method that was developed to document wetland characteristics and produce a relative index of freshwater wetland condition. RIRAM favors estimation over interpretation to maximize objectivity. The RIRAM index is produced by rating and summing stressor intensity and wetland integrity, which closely follows EPA wetland monitoring and 
assessment guidelines (U.S. EPA 2006). Specifically, three sub-indices evaluating landscape stresses, in-wetland stresses, and the integrity of wetland functional characteristics are evaluated in the field and summed to generate a single index of general wetland condition (App. 1). The RIRAM index is based on 100 possible points, comprising ten metrics, each carrying ten points. A score of 100 indicates undisturbed condition, and scores approaching zero would indicate extremely disturbed conditions. RIRAM scoring is based on the assumption that the impacts of diverse human disturbances additively contribute to the degradation of general wetland condition (U.S. EPA 2006; Fennessy et al. 2004). RIRAM meets EPA criteria for establishing wetland reference conditions (sensu, U.S. EPA 2006; FaberLangendoen et al. 2010).

RIRAM data were collected in a separate survey (Kutcher and Bried 2014), one season prior to the vegetation surveys. Because RIRAM is partly subjective, a single investigator conducted all RIRAM assessments for consistency. The perimeter and multiple transects of each site were accessed when possible on foot or by canoe, otherwise assessments were made by accessing and observing as many areas within and around the site as possible. Field maps of each assessment site, produced using GIS, were used for field orientation and determining wetland community and buffer characteristics. Each map contained a backdrop of leaf-off, color aerial photography at a scale sufficient to illustrate wetland habitats and surrounding land uses, and included a delineation of the site, delineations of 30-m and 150-m buffer-zones, a scale bar, and other identifying information. Data obtained during field investigations were recorded 
on RIRAM field datasheets (App. 1) and complemented using GIS analysis before data entry, as outlined in the RIRAM User's Guide.

Odonata Index of Wetland Integrity. We used the Odonata Index of Wetland Integrity (OIWI) as a biological reference measure of wetland disturbance (Kutcher and Bried 2014). OIWI uses the aggregate conservatism of adult (winged) dragonflies and damselflies (Insecta: Odonata) to indicate the relative ecological condition at a given wetland assessment unit. Odonate $\mathrm{CC}$ were generated empirically by relating recent survey data from a statewide Odonata atlas dataset to landscape features according to Kutcher and Bried (2014). Briefly, GIS analysis was used to determine the proportion of cultural land cover (i.e. developed and agricultural) within $300 \mathrm{~m}$ of Odonata survey points. Land cover proportions were used to assign disturbance classes, representing most-disturbed, intermediately disturbed, and least-disturbed wetlands, to the survey points. The $\mathrm{CC}$ were generated by the relative proportion of times a species was observed in each of the three disturbance categories. For the current study, we refined odonate $\mathrm{CC}$ using additional survey data to Kutcher and Bried's (2014) analysis. Using existing atlas data, the OIWI value for each of our 20 study sites was calculated as the mean CC of odonate species observed at the site.

\section{Relating FQA indices to reference conditions}

Statistical analyses were conducted using WinSTAT® statistical software (2006, R. Fitch Software) appended to Microsoft Excel® spreadsheet software. Rankbased and non-parametric methods were used in most statistical analyses to compensate for the ordinal nature of the RIRAM data and for the skews and gaps inherent in the samples. Spearman rank correlation analysis was used to determine 
which FQA index was best correlated with OIWI, RIRAM, and ISA values.

Additionally, box-and-whisker analysis was applied to evaluate FQA sensitivity to reference designations, following Barbour et al. (1996). Specifically, three reference classes were designated to the sites, based on 25th and 75th percentile RIRAM and ISA index values, to identify most-disturbed (degraded) and least-disturbed (reference-standard) thresholds, respectively (Stoddard et al. 2006). All other sites (those with index values falling between the $25^{\text {th }}$ and $75^{\text {th }}$ percentiles) were considered intermediately-disturbed. The degree of overlap in the distribution of FQA values among these classes was used to evaluate FQA index performance, where nonoverlapping FQA index interquartile ranges (boxes) within most-disturbed and leastdisturbed reference designations indicate high sensitivity to disturbance and excellent metric performance, whereas various degrees of interquartile-median overlap indicate lower sensitivity and performance (Barbour et al. 1996; Veselka et al. 2010).

\section{Reduced Effort Analysis}

The effects of reduced sampling effort on the performance of FQA indices were tested by re-calculating each FQA index with a sub-set of the data from each site, and then re-running statistical analyses for comparison against full-effort results. We assessed the effect of reducing effort in three ways: reducing the number of transects sampled, reducing the number of plants used per transect, and reducing both. Specifically, FQA indices calculated using vegetation data from a single (first) transect were compared with values using all three transects. Next, FQA indices calculated using only species with $\geq 10 \%$ cover (ranks 2 and 3 ) were compared to indices calculated with species from all cover classes. Finally, FQA indices calculated 
using only species with $\geq 10 \%$ cover surveyed in the first transect were compared with indices using all species in all transects.

\section{Results}

Our 20 wetland study sites ranged in size from 0.3 to 30 acres with a mean of 6.3 acres, and fell into three hydrogeomorphic classes (modified from Brinson 1993): isolated depression $(n=10)$, connected depression $(n=5)$, and floodplain riverine $(n=$ 5). The most commonly represented vegetation classes (per Cowardin et al. 1979) were emergent (in 20 sites), scrub-shrub (in 15 sites), and forested (in 12 sites) wetlands. According to RIRAM data, the most commonly observed stresses within sites were dams, roads, and multiple (a combination of stresses), whereas the most common surrounding landscape stresses were raised roads, footpaths, and residential development. Sixty percent $(60 \%)$ of the sites were impounded by dams or roads, and $60 \%$ were partly filled to upland grade, primarily from public roads and development filling. Sixteen invasive plant species were identified within 11 of the sites (Invasive Plant Atlas of New England 2011). Common reed (Phragmites australis) was the most common invader (25\% of the sites). Invasive species cover ranged from none noted (45\% of the units) to high (51-75\% cover at $10 \%$ of the units).

The vegetation surveys revealed 281 vascular plant species, of which 27 (10\%) were classified as non-native and $10(3.6 \%)$ were classified as Rhode Island State Heritage (rare) species. The number of species identified per site ranged from 19 to 96 with a mean of $50 \pm 21$ and the percentage of non-native species ranged from 0 to 28\%. The OIWI values ranged from 4.68 to 7.29 with a mean of $5.92 \pm 0.80$; RIRAM 
values ranged from 44.2 to 100 with a mean of $79.9 \pm 18.2$; and ISA values ranged from 0.00 to $62.4 \%$ with a mean of $11.5 \pm 17.1 \%$ (Table 2 ).

\section{FQA Variant Performance}

Differences among sites in four FQA index variants and in the proportion of native species (\% Native) were strongly correlated with our reference measures (OIWI, RIRAM, and ISA), and none of these variants incorporated proxies of species richness. The remaining two FQA indices, both of which incorporate information of species richness, were not correlated with any reference measures and nor was the number of native species identified. The total number of species identified increased with increasing disturbance according to RIRAM (Table 3). In contrast, both proxies of species richness, and the two floristic variants incorporating those proxies, were strongly influenced by hydrogeomorphic class, whereas the other four FQA indices were unaffected by hydrogeomorphology (Table 4).

Mean $C C_{s}$, Weighted Mean $C C_{s}$, and \% Native index values were most strongly correlated across the reference measures $\left(r_{s}>0.80\right.$ across all, Table 3$)$, and were thus considered best-fit metrics in further analyses. The variant $F Q A I^{\prime}$ was not included as a best-fit metric because it is functionally similar to the morestraightforward Mean $C C_{s}$ (discussed below). The best-fit metrics were significantly correlated with several of the component metrics of the RIRAM index, suggesting that a wide range of anthropogenic factors contributed to floristic variability (Table 5).

Distributions of Mean $C C_{s}$ and Weighted Mean $C C_{s}$ values were completely non-overlapping between least-disturbed and most-disturbed reference categories identified by RIRAM and ISA (Fig. 1). In contrast, the distributions of FQAI values 
between least-disturbed and most-disturbed categories overlapped nearly completely according to both reference measures. The FQAI distribution showed a tendency toward higher values with intermediate disturbance according to RIRAM designations (Kruskal-Wallace, $H=5.1, P=0.08, n=3$ ).

Reduced Sampling Effort

Single-transect vegetation sampling of all cover classes (ranks 1-3) produced 15 to 71 vascular plant species per unit with a mean of $39 \pm 17$; three-transect sampling of only rank 2 and 3 cover classes ( $\geq 10 \%$ total cover) produced 3 to 10 species per unit with a mean of $6.1 \pm 2.1$; and single-transect sampling of only rank 2 and 3 cover classes produced 3 to 12 species per unit with a mean of $6.9 \pm 2.4$. The strength of correlations between the best fit floristic indices and the reference measures declined incrementally as sampling effort was reduced; this decline was most pronounced for \% Native with a reduction in cover classes sampled (Table 6).

\section{Discussion}

Assumptions of FQA

The various FQA metrics rely on underlying assumptions that are central to their functionality as indicators of freshwater wetland integrity. Evaluating the validity of these assumptions should clarify the utility of the FQA variants. Because they are being applied to indicate broad wetland integrity rather than any single stressor, all FQA variants operate under the general assumption that they will respond monotonically to the cumulative effects of a range of human disturbances (U.S. EPA 2002). All variants also rely on the broad assumption that the signal of disturbance is 
stronger than the signal of environmental noise caused by inherent variations in other factors such as wetland size, species composition, basin morphology, and hydrology (Bried et al. 2013).

Each individual species is ranked according to its perceived tolerance of human impacts (= conservatism). Averaging these coefficients of conservatism across species assumes that aggregating the responses of individual species to various human disturbances will reflect the cumulative impacts of those disturbances. To support the signal of aggregate conservatism, variants incorporating species richness must, then, rely on the assumption that the number of native (or total) species identified at a wetland will also decline with increasing disturbance. Variants excluding non-native species operate under the assumption that non-native species are irrelevant to aggregate conservatism, as they are not original inhabitants and thus cannot be evaluated on that scale (Swink and Wilhelm 1979). And, in the context of assessing wetland integrity (as opposed to conservatism, per se), the deliberate exclusion of nonnative species must also assume that non-native species confound the signal of wetland health. Conversely, variants incorporating non-native species hold the assumption that non-native species are non-conservative (i.e. tolerant to disturbances) and meaningfully vary with wetland health. Lastly, variants incorporating species abundance operate under the assumption that the relative abundance of species provides important information over their presence alone.

Implications of empirical analysis

Evaluated against our three reference measures (ISA, RIRAM, OIWI), the original FQAI did not effectively indicate wetland condition across our study sample, 
whereas FQA variants excluding species richness (Mean $\mathrm{CC}_{n}$, Mean $\mathrm{CC}_{s}$, Weighted Mean $C C_{s}$, and $F Q A I^{\prime}$ ) were strongly correlated with all three reference measures; those richness-free variants incorporating non-native species (Mean $\mathrm{CC}_{s}$, Weighted Mean $C C_{s}$, and $F Q A I^{\prime}$ ) outperformed the variant based strictly on native species $\left(\right.$ Mean $C C_{n}$ ); and additionally incorporating species cover increased performance further (Weighted Mean $C C_{s}$ ). Interestingly, the percentage of native species alone (\% Native) was most-strongly correlated with RIRAM and ISA in full-effort sampling. Based on the empirical outcomes, our findings suggest that richness confounded the FQA models; non-native species were important and perhaps driving components of FQA functionality; and species abundance enhanced FQA performance.

Consistently strong correlations with our reference measures demonstrate the ability of the best-fit (richness-free) FQA variants to respond to indirect (ISA) and direct (RIRAM) stresses and impacts, and support the validity of FQA as a meaningful biological indicator, responding in concert with, or perhaps as a factor in, the response of Odonata species aggregate conservatism (OIWI). Non-overlapping interquartile ranges between least-disturbed and most-disturbed categories in box plot analyses indicate excellent sensitivity of the best-fit floristic variants to categories of wetland disturbance (per Barbour et al. 1996).

Strong, significant correlations of the best-fit variants with multiple RIRAM metrics and submetrics suggest the efficacy of floristic assessment measures in integrating and reflecting the cumulative impacts of wetland disturbances, a desirable trait for the broad assessment of ecological integrity (Karr and Chu 1999). Interestingly, none of the floristic measures was strongly correlated with RIRAM 
metrics rating hydrologic modification, including impoundment, draining or diversion of water, and apparent hydrologic integrity, even though $60 \%$ of the units were at least partly impounded. This suggests that hydrologic modification does not strongly affect the aggregate conservatism or proportional nativeness of plant species, even though it is known to largely control species composition (Mitsch and Gosselink 2000). It further implies a resilient adaptability of wetlands to hydrologic change, suggests that impoundment does not favor non-native over native species, and suggests the potential for high quality wetlands to persist in artificial water regimes. In this light, FQA may not be a reliable indicator of hydrologic modifications. More study is needed to clarify the response of floristic quality to specific human disturbances.

\section{Floristic conservatism as an indicator of wetland integrity}

Aggregate conservatism of native species (Mean $C C_{n}$ ) — a strictly independent measure from species richness and from the proportion of native species-was strongly correlated with all three of our reference measures, suggesting that aggregate conservatism (according to our $\mathrm{CC}$ ) is an effective indicator of wetland condition.

Additionally, correlation with our additive, multi-metric assessment measure (RIRAM) suggests that plant conservatism is sensitive to cumulative wetland degradation, allowing assessment across the continuum of wetland integrity (U.S. EPA 2002; Faber-Langendoen 2009). Conservatism is grounded in the most basic ecological tenet of competitive exclusion, wherein environmental conditions will favor certain species to the competitive exclusion of others. Conservatism simply holds that habitat disturbances will create conditions that favor disturbance-tolerant species to 
the exclusion of conservative species. Thus, conservatism is intuitively relevant as an indicator of environmental degradation, or loss of integrity.

In theory, aggregate plant species conservatism is an exemplary indicator for assessing freshwater wetland integrity. It is easily measured and non-destructive; it is broadly applicable, as vascular plants occur in most wetlands; its response is easily understood and interpreted; it measures a wetland characteristic that is closely tied to management concerns; and our findings suggest that it is integrative, aggregating the responses of multiple species to various human disturbances (Cairns et al. 1993; Dale and Bayler 2001; Karr 2006).

Species richness as a component of FQA

Species richness is a commonly used attribute in biological assessment, generally used as a proxy for community diversity, which is considered to reflect conservation value and increase habitat productivity, resiliency, and functionality (Tilman et al. 1996; Knops et al. 1999; Myers et al. 2000; Rosset et al. 2013). These benefits suggest that increasing species richness should therefore indicate increasing habitat quality. But these assumptions are not functionally applicable to the assessment of ecological integrity (Keough and Quinn 1991). Foremost, the Intermediate Disturbance Hypothesis (Connell 1978) predicts that species richness should increase with moderate disturbance and then decrease with severe disturbance, thus species richness does not consistently follow the monotonic trend best suited for reliable indicator function. In the human-dominated landscapes that are now almost universal in our study region, disturbances favor fast-growing opportunistic colonizers, such as ubiquitous invasive species (Didham et al. 2005). And while 
invasive species domination can decrease species richness at the patch level (Silliman and Bertness 2004), patchy or incomplete incursions (indicating intermediate disturbance) should increase richness at the habitat level, a hypothesis our findings support (Catford et al. 2012). Moreover, high species richness is not a necessary hallmark of productive, resilient habitats (Grime 1997). For example, salt marshes are among the most productive, stable, and important ecosystems on earth, even as they are low in species diversity (Waide et al. 1999).

Additionally, the number of species identified at a site is a function of site area and sampling effort (Connor and McCoy 1979; Gotelli and Colwell 2001; Rooney and Rogers 2002). In theory, FQA requires a complete floristic inventory, but this is not often practical, particularly for large or complex areas. Our belt-transect sampling method was designed to normalize effort according to site area, yet floristic measures incorporating species richness tended to vary with site area. Fully standardizing sampling effort could potentially lessen those effects, but a small standardized sample size would diminish the FQA mechanism and accuracy of richness estimates in larger or more complex sites, whereas a large standardized sample size would increase effort to an impractical level. Bourdaghs et al. (2006) addressed this conundrum by averaging $F Q A I$ scores from several equal-sized subunits within a site. But, their method diminishes the metric's intended mechanism of quantifying the benefits of site-level species richness, and does not address the potential confounding effects of species richness increasing with intermediate disturbance.

We found that species richness clearly impeded the ability of FQA indices to predict wetland condition. In their seminal FQA study, Lopez and Fennessy (2002) 
applied the original FQAI to 20 depressional wetlands and found that FQAI was significantly correlated with a disturbance index that evaluated buffer condition within $100 \mathrm{~m}$, but subsequent studies have found that variants excluding species richness more reliably vary with wetland condition (Cohen et al. 2004; Miller and Wardrop 2006; Matthews et al. 2009; Vaselka et al. 2010; Bried et al 2013). Indeed, our current study found that native species richness $(N)$ was not correlated with any measure of wetland condition, and that total species richness $(S$; driven by non-native species richness) increased with greater disturbance according to RIRAM, a trend that counteracts the decrease in conservatism (with increased disturbance) that drives FQA evaluation.

Moreover, we found that richness-weighted measures varied with hydrogeomorphic class, consistent with other recent findings (Bried et al. 2013). This suggests that species richness is innately variable across wetland types (independent of condition). In practice, richness-weighted metrics should therefore necessitate additional classification restrictions compared to metrics based on conservatism alone. Reduced classification restrictions can benefit ecological assessment programs because classification parameters are partly subjective and therefore add assessment bias, and because such restrictions diminish the user's capability to compare the relative condition of wetlands varying in size and type. So, although FQAI could conceivably be appropriate in situations where native species richness is known to monotonically decrease with increased disturbance (e.g. wetlands of similar type and size), ecological theory clearly predicts that richness will more-often confound the indicator value of FQA, as supported by our empirical findings. We therefore 
recommend that practitioners avoid using richness-weighted FQA variants, reserving richness proxies of native, total, and non-native species as separate metrics to be interpreted with respective cautions and in the appropriate context.

Non-native species and FQA

Of the FQA variants designed to eliminate the effects of species richness, those incorporating non-native species (Mean $C_{s}$, Weighted Mean $C C_{s}$, and $\left.F Q A I^{\prime}\right)$ were most-strongly associated with our reference measures. Cohen et al. (2004) reported slightly-improved performance by including non-native species in Mean CC (Mean $C C_{s}$ over Mean $C C_{n}$ ), whereas later studies report no performance differences among FQA metrics with and without non-native species incorporated (Bourdaghs et al. 2006; Miller and Wardrop 2006). FQA variants that include non-native species generally assume that all non-native species are tolerant to, or thrive on human disturbances (i.e. are non-conservative), as implied by the default CC designation of zero (0). While this cannot be absolutely true, due to inherent variation among species, our findings strongly suggest that non-native species enhance FQA indication of wetland integrity.

The prevalence of non-native species alone (\% Native), was strongly correlated with our reference measures and with multiple RIRAM component metrics, suggesting its broad indication of wetland integrity, and supporting the assumption that non-native species are inversely linked to ecological integrity. Ervin et al. (2006) similarly found that non-native species richness outperformed FQAI in indicating wetland disturbance, and contend that, because non-native species are integral in wetland species composition, non-native species should be included in FQA unless 
otherwise indicated. Our study region is widely developed and dominated by novel ecosystems containing few to many non-native species. The \% Native metric may not perform as well in less-developed areas containing fewer opportunities for non-native species establishment, and the influence of native species conservatism may dominate. Additionally, relative nativeness may not be as reliable a measure of human disturbance across broad conservation areas containing multiple habitat types (Vacher et al. 2007). However, \% Native is ecologically relevant at the wetland site level even in the absence of empirical support. Non-native species both indicate human disturbances and diminish wetland integrity, in that they are often fast-growing colonizers that can establish quickly following disturbances and, subsequently, can outcompete native species for critical resources, degrade habitat value for native fauna, and diminish a host of other ecosystem values (Didham et al. 1996).

The formulas of two richness-free FQA variants that incorporate non-native species, Mean $C C_{s}$ and $F Q A I^{\prime}$, may appear dissimilar, but in function they are nearly equivalent. Miller and Wardrop (2006) present FQAI' as "FQAI relative to maximumattainable $F Q A I^{\prime}$ (Table 1 second column), but this is algebraically equivalent to the product of Mean $C C_{n}$ and the square root of the proportion of native species $(\times 10$, which in relative terms is irrelevant). Similarly, because the assigned CC for any nonnative species is typically zero (0), Mean $C C_{s}$ is equivalent to the product of Mean $C C_{n}$ and the proportion of native species (\% Native; Table 1, fourth column). So functionally, FQAI' only differs from Mean $C C_{s}$ in that the effects of non-native species are reduced by applying the square root in the former. Equal performance of FQAI' and Mean $C C_{n}$ (Miller and Wardrop 2006), coupled with improved 
performance of Mean $C C_{s}$ over Mean $C C_{n}$ (Cohen et al. 2004; this study), suggest that buffering the proportion of native species is unnecessary or perhaps counterproductive.

The straightforward Mean $C C_{s}$ (simply the mean conservatism of all species) thus prevails as the most effective and parsimonious measure among non-weighted FQA variants. Additionally, because $M e a n C C_{s}$ is equivalent to the product of Mean $C C_{n}$ and $\%$ Native, these attributes could also be evaluated separately to increase user understanding of assessment outcomes, as they can indicate the extent of non-native invasion and the integrity of the remaining native population. Combined, the utility and simplicity of Mean $C C_{s}$ may benefit practitioners seeking an understandable and reliable single metric with which to evaluate general wetland condition. Incorporating Abundance in FQA

Although Mean $C C_{s}$ may indeed be a straightforward and efficient indicator of wetland condition, it is functionally incomplete. Species composition is commonly described in terms of identity, species richness, and abundance (often relative abundance). While species richness often confounds disturbance measures, both identity (represented by Mean $C C_{s}$ ) and relative abundance are relevant and practical for describing site conditions. Cohen et al. (2004) found that Weighted Mean $C C_{n}$ slightly outperformed Mean $C C_{n}$, suggesting that incorporating species abundance could improve metric performance. Further improvement should be gained by incorporating non-native species (Weighted Mean $C C_{s}$, Table 1) for reasons offered above, and indeed Weighted Mean $C C_{s}$ performed better than Mean $C C_{s}$ in this current study. But the ecological and practical implications of abundance in FQA are relevant 
even in the absence of such empirical improvement; this can be clarified if taken to a reasonable extreme. Consider two wetlands with identical plant species but differing in that one is dominated by an aggressive non-native invader, such as the common reed Phragmites australis, with a remnant section of native vegetation, whereas the other is dominated by native vegetation with a single stem of $P$. australis. Measured by Mean $C C_{s}$, the two wetlands would be scored equally. In contrast, Weighted Mean $C C_{s}$ would incorporate and reflect habitat degradation associated with $P$. australis domination, lowering the index value. Among wetlands with more even species distributions, Weighted Mean $C C_{s}$ would function nearly equivalently to Mean $C C_{s}$. The weighted FQA variant therefore provides a more relevant and defensible indication of wetland condition at the site scale, which is particularly important for comparing assessment outcomes.

\section{Sampling Effort and Performance}

Practitioners must consider three matters associated with sampling effort in floristic assessment. The first and primary consideration is index performance (reliability); the second is the logistical feasibility of the method in terms of available botanical expertise; and the third is the feasibility of the method in terms of the amount of time the method takes. Our full-effort sampling time was practical, usually completed in less than three hours of field work and an hour or two of laboratory support. Botanical expertise may therefore pose the most likely limitation to practitioners. A reduction in the number of transects sampled per unit (from three to one) had the smallest (of the reduced-effort methods evaluated) negative effect on best-fit metric performance and could reduce in-wetland sampling time by as much as 
$67 \%$. But because most species are typically identified in the first transect, singletransect sampling would not alleviate limitations of botanical expertise or reduce laboratory identification time. Even single-transect assessment using \% Native would not alleviate botanical expertise limitations because the investigator would still need to identify all species observed to determine their nativeness.

In contrast, reduced cover-class sampling greatly reduces species identification requirements (from a mean of 50 species per wetland for full-effort sampling to a mean of 6 or 7 and as few as 3), greatly alleviating expertise and time limitations; but it also reduces precision. Our findings suggest that this loss may be inversely related to the complexity of the FQA model. The precision of \% Native, based only on the proportion of nativeness, declined considerably using reduced-cover-class sampling; Mean $C C_{s}$, which incorporates proportional nativeness and conservatism (see Table 1, last column), was less-strongly affected; and the precision of Weighted Mean $C C_{s}$, which incorporates proportional nativeness, conservatism, and relative abundance, was not strongly affected. Lastly, reduced sampling of transects and cover-classes incrementally decreased floristic metric performance, relative to RIRAM and ISA. Most effective FQA Variants

Overall, the abundance-weighted Weighted Mean $C C_{s}$ slightly outperformed Mean $C C_{s}$ against our reference measures and was the most stable floristic measure in maintaining indicator precision when cover-class sampling effort was reduced. Prior studies suggest that the apparent increase in effectiveness gained by incorporating abundance classes is not worth the extra sampling effort (Cohen et al. 2004; Bourdaghs et al. 2006). But the sampling methods developed for this study, which 
focused on species identification and the estimation of broad cover classes, added little extra effort over identity sampling alone $(\sim 3 \mathrm{~min}$. per transect $\times 3$ transects $=\sim 9 \mathrm{~min}$. per unit for full-effort sampling), and applying the cover classes to Mean $C C_{s}$ was a straightforward spreadsheet operation. Furthermore, the apparent increased stability of Weighted Mean $C C_{s}$ (over the other floristic measures) with a reduction in cover-class sampling effort suggests resilience to sampling biases, and may be important in cases where reduced-effort sampling is appropriate. We believe that the increased precision of Weighted Mean $C C_{s}$ is worth the small added increase in effort, particularly for evaluating individual wetlands. And although Weighted Mean $C C_{s}$ is operationally somewhat more complex than Mean $C C_{s}$, the concept remains straightforward and intuitive: mean conservatism of all species, weighted by relative cover. We therefore recommend Weighted Mean $C C_{s}$ for wetland condition categorizations, and the components Mean $\mathrm{CC}_{n}$ and \% Native for further interpreting the ecological significance of the results.

\section{Methodology}

Our vegetation sampling method for abundance-weighted metrics applied three cover classes to increase producer precision (repeatability) at the cost of accuracy. Using five or six cover classes is a more common approach for estimating vegetation cover (Mueller-Dombois and Ellenberg 1974), but this is typically applied to smaller plots from which cover classes are easier to estimate, compared with the long, wide transects used in this study. Estimating five cover classes could potentially increase the precision of the Weighted Mean $C C_{s}$, but could also require additional time estimating cover per transect in the field. The small increase in the performance of 
Weighted Mean $C C_{s}$ relative to Mean $C C_{s}$ suggests that further gains associated with more precise cover classes may be unnecessary to retain the benefits of weighted sampling discussed above.

The tradeoff between practicality and reliability of the FQA method will need to be considered for implementation, perhaps on a per-project basis. Critical applications of floristic assessment would be best-served by running the full sampling method and applying the data to Weighted Mean $C C_{s}$. Running reduced-cover-class sampling across three transects and applying the data to Weighted Mean $C C_{s}$ could potentially be an efficient method for less critical evaluations, but this needs further study before it is put into practice. Testing the best-fit FQA metrics and sampling methods on a larger study sample would clarify these tradeoffs, which would be helpful in developing more specific protocols for FQA implementation.

This study not only validates FQA, it also further supports the use of ISA, RIRAM, and OIWI. While these measures are not entirely independent from each other (e.g. both ISA and RIRAM, in part, incorporate landscape condition), they were developed using a priori ecological principles and not by their inter-correlation or correlation with any other single measure. It is therefore possible to evaluate these measures against each other, and to use them in combination to increase assessment reliability, or to better inform management. While this approach reduces the circularity of calibration and reduces reference measure bias, our methods did not alleviate the limitations of our study sample, which included only open-canopy vegetated wetlands. Recent work has indicated that FQA may not be as effective in forested wetlands (T. Portante, unpublished data). We recommend a rigorous study using multiple 
independent reference measures for developing floristic variants best suited for forested wetlands.

\section{Conclusion}

We used empirical validations and ecological theory to assess the underlying assumptions and clarify the mechanisms of FQA. Our analysis discredits the assumption that species richness supports FQA functionality by declining predictably with wetland integrity. To the contrary, our findings suggest that richness will more often confound FQA function without providing predictably meaningful information. Our analysis supports the assumptions that aggregate conservatism will decline predictably with increasing human disturbance; non-native species are relevant to aggregate conservatism and effective in reflecting wetland ecological integrity; and the relative abundance of species provides important information over species presence alone. Our analysis suggests that the abundance-weighted FQA metric incorporating non-native species responds meaningfully and predictably across a gradient of ecological degradation, is relevant at the site level, and is resistant to the confounding influences of unit size, sampling effort, and wetland type. As such, the straightforward principles and methods of FQA can provide practitioners with a set of practical, reliable, and informative tools for assessing freshwater wetland integrity.

Our methods demonstrate that a straightforward bioindicator can predictably integrate and reflect the complex signal of cumulative environmental degradation. Our empirical validation against three independently-derived reference measures broadened the signal of wetland integrity and avoided circularity among our measures. And, because we evaluated the significance of our empirical findings against 
ecological principles, we are confident that our resulting indicator is responding to the signal of disturbance over the biases of our reference measures, and we understand the implications of that response for interpreting assessment outcomes. We recommend a method of bioindicator validation that focuses on the relevance of indicator response to reference conditions represented by multiple measures.

\section{Acknowledgments}

We thank Carolyn Murphy, Keith Killingbeck, Rick McKinney, Evan Preisser, and Jason Bried for providing technical advice. David Gregg, Susan Kiernan, and Carolyn Murphy administered this work, and Stacey Liecht Young, Grace Lentini, and Rick Enser assisted with vegetation sampling and data summary. Kerry Strout and Jason Bried coordinated the regional assignment of floristic coefficients of conservatism, and Rick Enser assigned the coefficients of conservatism applied in this study. Rhode Island Natural History Survey is housed by the University of Rhode Island, College of the Environment and Life Sciences. This project was funded by the Rhode Island Department of Environmental Management, Office of Water Resources, through a Wetlands Program Development Grant awarded by the United States Environmental Protection Agency.

\section{Literature Cited}

Barbour, M. T., J. Gerritsen, G. E. Griffeth, R. Frydenborg, E. McCarron, J. S. White, and M. L. Bastain. 1996. A framework for biological criteria for Florida 
streams using benthic macroinvertebrates. Journal of the North American Benthological Society 15:185-211.

Birk, S., W. Bonne, A. Borja, S. Brucet, A. Courrat, S. Poikane, A. Solimini, W. Van de Bund, N. Zampoukas, and D. Hering. 2012. Three hundred ways to assess Europe's surface waters: an almost complete overview of biological methods to implement the Water Framework Directive. Ecological Indicators 18:31-41.

Bourdaghs, M., C. A. Johnston, and R. R. Regal. 2006. Properties and performance of the floristic quality index in Great Lakes coastal wetlands. Wetlands 26:718735.

Bried, J. T., K. L. Strout, and T. Portante. 2012. Coefficients of conservatism for the vascular flora of New York and New England: inter-state comparisons and expert opinion bias. Northeastern Naturalist, in press.

Bried, J. T., S. K. Jog, and J. W. Matthews. 2013. Floristic quality assessment signals human disturbance over natural variability in a wetland system. Ecological Indicators 34:260-267.

Brinson, M. M. 1993. A hydrogeomorphic classification for wetlands. Final Report to the U.S. Army Corps of Engineers. Waterways Experiment Station, Vicksburg, MS, USA. Technical Report WRP-DE-4.

Cairns Jr., J., P. V. McCormick, and B. R. Niederlehner. 1993. A proposed framework for developing indicators of ecosystem health. Hydrobiologia 263:1-44.

Catford, J. A., et al. 2012. The intermediate disturbance hypothesis and plant invasions: Implications for species richness and management. Perspectives in Plant Ecology, Evolution and Systematics 14:231-241. 
Cohen, M. J., S. Carstenn, and C. R. Lane. 2004. Floristic quality indices for the assessment of depressional marsh condition in Florida. Ecological Applications 14:784-794.

Connell, J. H. 1978. Diversity in tropical rain forests and coral reefs. Science 199:1302-1310.

Connor, E. F. and E. D. McCoy. 1979. The statistics and biology of the species-area relationship. American Naturalist 113:791-833.

Cowardin, L.M., V. Carter, F. C. Golet, and E. T. LaRoe, E.T. 1979. Classification of wetlands and deepwater habitats of the United States. Office of Biological Services, Fish and Wildlife Service, U.S. Department of the Interior, Washington, DC.

Dale, V. H., and S. C. Beyeler. 2001. Challenges in the development and use of ecological indicators. Ecological Indicators 1:3-10.

Didham, R. K., J. M. Tylianakis, M. A. Hutchison, R. M. Ewers, and N. J. Gemmell 2005. Are invasive species the drivers of ecological change? Trends in Ecology \& Evolution 20:470-474.

Ervin, G. N., B. D. Herman, J. T. Bried, and D. C. Holly. 2006. Evaluating non-native species and wetland indicator status as components of wetland floristic assessment. Wetlands 26:1114-1129.

Faber-Langendoen, D., R. Lyons, and P. Comer. 2009. Developing options for establishing reference conditions for wetlands across the lower 48 states. A report to the U.S. Environmental Protection Agency. NatureServe, Arlington, VA. $51 \mathrm{pp}$. 
Fennessy, M. S., A. D. Jacobs, and M. E. Kentula. 2004. An evaluation of rapid methods for assessing the ecological condition of wetlands. Wetlands 27:543560.

Gotelli, N. J. and R. K. Colwell. 2001. Quantifying biodiversity: procedures and pitfalls in the measurement and comparison of species richness. Ecology Letters 4:379-391.

Grime, J. P. 1997. Biodiversity and Ecosystem Function: The Debate Deepens. Science 277:1260-1261.

Karr, J. R. 1991. Biological integrity: a long-neglected aspect of water resource management. Ecological Applications 1:66-84.

Karr, J. R. 2006. Seven foundations of biological monitoring and assessment. Biologia Ambientale 20:7-18.

Karr, J. R. and E. W. Chu. 1999. Restoring Life in Running Waters; Better Biological Monitoring. Island Press, Washington, DC.

Keough, M. and G. Quinn. 1991. Causality and the choice of measurements for detecting human impacts in marine environments. Marine And Freshwater Research 42:539-554.

Kentula, M. E. 2000. Perspectives on setting success criteria for wetland restoration. Ecological Engineering 15:199-209.

Knops, J., D. Tilman, D. Haddad, S. Naeem, C. E. Mitchell, J. Haarstad, M. E. Ritchie et al. 1999. Effects of plant species richness on invasion dynamics, disease outbreaks, insect abundances and diversity. Ecology Letters 2:286-293. 
Kutcher, T. E. 2011. Rhode Island rapid assessment method user's guide; RIRAM version 2.10. Rhode Island Department of Environmental Management, Office of Water Resources, Providence, RI. 30 pp.

Kutcher, T. E. and J. T. Bried. 2014. Adult Odonata conservatism as an indicator of freshwater wetland condition. Ecological Indicators 38:31-39.

Lopez, R. D. and M. S. Fennessey. 2002. Testing the floristic quality assessment index as an indicator of wetland condition. Ecological Applications 12:487-497.

Matthews, J. W., G. Spyreas, and A. G. Emdress. 2009. Trajectories of vegetationbased indicators used to assess wetland restoration progress. Ecological Applications 19:2093-2107.

Myers, N., R. A. Mittermeier, C. G. Mittermeier, G. A. B. Da Fonseca, and J. Kent. 2000. Biodiversity hotspots for conservation priorities. Nature 403:853-858.

Miller, S. J., and D. H. Wardrop. 2006. Adapting the floristic quality assessment index to indicate anthropogenic disturbance in central Pennsylvania wetlands. Ecological Indicators 6:313-326.

Mitsch, W. J. and J. G. Gosselink. 2000. Wetlands, Third Edition. John Wiley and Sons, New York. 920 pp.

Mueller-Dombois, D., and H. Ellenberg, 1974. Aims and Methods of Vegetation Ecology. Wiley, New York. 547 pp.

Niemi, G. J. and M. E. McDonald 2004. Application of ecological indicators. Annual Review of Ecology, Evolution, and Systematics 89-111.

Rooney, T. P. and D. A. Rogers. 2002. The Modified Floristic Quality Index. Natural Areas Journal 22:340-344. 
Rosset, V., J. P. Simaika, F. Arthaud, G. Bornette, D. Vallod, M. J. Samways, and B. Oertli. 2013. Comparative assessment of scoring methods to evaluate the conservation value of pond and small lake biodiversity. Aquatic Conservation: Marine and Freshwater Ecosystems 23:23-36.

Sifneos, J. C., A. T. Herlihy, A. D. Jacobs, M. E. Kentula. 2010. Calibration of the Delaware Rapid Assessment Protocol to a comprehensive measure of wetland condition. Wetlands 30:1011-1022.

Silliman, B. R. and M. D. Bertness. 2004. Shoreline development drives invasion of Phragmites australis and the loss of plant diversity on New England salt marshes. Conservation Biology 18:1424-1434.

Stoddard, J. L., D. P. Larsen, C. P. Hawkins, R. K. Johnson, and R. H. Norris. 2006. Setting expectations for the ecological condition of streams: the concept of reference condition. Ecological Applications 16:1267-1276

Swink, F. and G. Wilhelm. 1979. Plants of the Chicago Region; Revised and Expanded Edition with Keys. The Morton Arboretum, Lisle, IL.

Tilman, D., D. Wedin, and J. Knops. 1996. Productivity and Sustainability Influenced by Biodiversity in Grassland Ecosystems. Nature 379:718-720.

U.S. EPA. 2002. Methods for evaluating wetland condition: Developing metrics and indexes of biological integrity. Office of Water, U.S. Environmental Protection Agency, Washington, DC. EPA 822-R-02-016.

U.S. EPA. 2006. Application of elements of a state water monitoring and assessment program for wetlands. Wetlands Division, Office of Wetlands, Oceans and 
Watersheds, U.S. Environmental Protection Agency, Washington, DC. EPA 841-B-03-003.

Vacher, K. A., K. T. Killingbeck, and P. V. August. 2007. Is the relative abundance of nonnative species an integrated measure of anthropogenic disturbance? Landscape Ecology 22:821-835.

Vaselka, W., J. S. Rentch, W. N. Grafton, W. S. Kordek, and J. T. Anderson. 2010. Using two classification schemes to develop vegetation indices of biological integrity for wetlands in West Virginia, USA. Environmental Monitoring and Assessment 170:555-569.

Waide, R. B., M. R. Willig, C. F. Steiner, G. Mittelbach, L. Gough, S. I. Dodson, G. P. Juday, and R. Parmenter. The relationship between productivity and species richness. Annual Review of Ecology and Systematics 1999:257-300. 
Table 1. Variants of the FQAI formula and their recent applications in freshwater wetland assessment

\begin{tabular}{|c|c|c|c|}
\hline $\begin{array}{l}\text { Metric } \\
\text { Variant }\end{array}$ & Formula $^{\mathrm{a}}$ & Applications & $\begin{array}{c}\text { Equivalent } \\
\text { Formula }\end{array}$ \\
\hline$F Q A I$ & $\frac{\sum C C}{N} \times \sqrt{N}$ & $\begin{array}{l}\text { Lopez and } \\
\text { Fennessy } 2002\end{array}$ & \\
\hline Mean $C C_{n}$ & $\frac{\sum C C}{N}$ & $\begin{array}{l}\text { Rooney and Rogers } \\
\text { 2002; Cohen et al. } \\
\text { 2004; Bourdaghs et } \\
\text { al. 2006; Miller and } \\
\text { Wardrop } 2006\end{array}$ & \\
\hline Mean $C C_{s}$ & $\frac{\sum C C}{S}$ & $\begin{array}{l}\text { Cohen et al. 2004; } \\
\text { Bourdaghs et al. } \\
\text { 2006; Matthews et } \\
\text { al. 2009; } \\
\text { Bried et al. } 2013\end{array}$ & Mean $C C_{n} \times \frac{N}{S}$ \\
\hline $\begin{array}{l}\text { Weighted } \\
\text { Mean } \mathrm{CC}_{n}{ }^{\mathrm{b}}\end{array}$ & $\frac{\sum\left(C C \times P_{n}\right)}{\sum P_{n}}$ & $\begin{array}{l}\text { Cohen et al. 2004; } \\
\text { Bourdaghs et al. } \\
2006\end{array}$ & \\
\hline $\begin{array}{l}\text { Weighted } \\
\text { Mean } C C_{s}\end{array}$ & $\frac{\sum\left(C C \times P_{s}\right)}{\sum P_{s}}$ & $\begin{array}{l}\text { Bourdaghs et al. } \\
2006\end{array}$ & \\
\hline$F Q A I^{\prime}$ & $\left(\frac{\sum C C}{N \times 10} \times \frac{\sqrt{N}}{\sqrt{S}}\right) \times 100$ & $\begin{array}{l}\text { Miller and Wardrop } \\
\text { 2006; Vaselka et al. } \\
2010\end{array}$ & Mean $C C_{n} \times \sqrt{\frac{N}{S}} \times 10$ \\
\hline$F Q A I_{s}$ & $\frac{\sum C C}{S} \times \sqrt{S}$ & $\begin{array}{l}\text { Bourdaghs et al. } \\
\text { 2006; Matthews et } \\
\text { al. 2009; } \\
\text { Bried et al. } 2013\end{array}$ & \\
\hline$\%$ Native & $\frac{N}{S}$ & Ervin et al. 2006 & \\
\hline
\end{tabular}

${ }^{\mathrm{a}} C C=$ plant species coefficient of conservatism; $N=$ number of native plant species

recorded; $S=$ total number of plant species recorded (including non-natives); $P_{n}=$ proportional cover of native plant species recorded and $P_{s}=$ proportional cover of all plant species recorded, ${ }^{b}$ not tested in this study 
Table 2. Values of floristic, Odonata, rapid, and landscape assessment indices of freshwater wetland condition from 20 wetland sites; $M C C_{n}=$ Mean $C C_{n} ; M C C_{s}=$ Mean $C C_{s} ; W M C C_{s}=$ Weighted Mean $C C_{s}$

\begin{tabular}{|l|c|c|c|c|c|c|c|c|c|c|c|c|c|}
\hline Site Code & $F Q A I$ & $F Q A I_{s}$ & $M_{n}$ & $M C C_{s}$ & $W_{n}$ & $M_{S}$ & $F Q A I^{\prime}$ & $N$ & $S$ & $\% N$ & $O I W I$ & $R I R A M$ & $I S A$ \\
\hline AUD-NEW-PND & 30.9 & 30.4 & 3.86 & 3.74 & 3.95 & 3.80 & 64 & 66 & 97.0 & 5.83 & 87.2 & 3.3 \\
\hline PRV-BLRD-PRK & 15.4 & 13.7 & 3.53 & 2.79 & 2.74 & 3.14 & 19 & 24 & 79.2 & 4.80 & 63.9 & 13 \\
\hline PRV-BOTH-PND & 30.4 & 30.4 & 4.69 & 4.69 & 4.59 & 4.69 & 42 & 42 & 100 & 6.82 & 93.7 & 0.3 \\
\hline PRV-BRCH-STA & 31.7 & 30.8 & 3.76 & 3.56 & 3.32 & 3.66 & 71 & 75 & 94.7 & 5.89 & 86.3 & 3.2 \\
\hline PRV-GLAC-PND & 24.8 & 23.3 & 4.45 & 4.06 & 4.20 & 4.31 & 31 & 33 & 93.9 & 6.24 & 82.0 & 6.3 \\
\hline PRV-JACK-SCPD & 32.3 & 32.3 & 4.43 & 4.43 & 4.06 & 4.43 & 53 & 53 & 100 & 5.95 & 84.9 & 1.6 \\
\hline PRV-LONS-MRSH & 28.5 & 26.2 & 3.81 & 3.25 & 2.86 & 3.54 & 56 & 65 & 86.2 & 4.92 & 57.6 & 19 \\
\hline PRV-MOSH-PND & 22.5 & 18.8 & 3.61 & 2.56 & 1.78 & 3.06 & 39 & 54 & 72.2 & 4.68 & 44.2 & 62 \\
\hline PRV-PYSZ-FEN & 28.3 & 27.9 & 4.85 & 4.71 & 5.13 & 4.78 & 34 & 35 & 97.1 & 6.34 & 88.8 & 3.1 \\
\hline PRV-SLTR-PRK0 & 31.3 & 28.9 & 3.85 & 3.30 & 2.77 & 3.56 & 66 & 77 & 85.7 & 5.30 & 50.4 & 31 \\
\hline PRV-WOON-STA3 & 29.0 & 26.3 & 3.87 & 3.24 & 3.25 & 3.57 & 56 & 66 & 84.8 & 4.96 & 54.9 & 38 \\
\hline PRV-WOON-STA4 & 25.6 & 22.5 & 3.95 & 3.06 & 3.19 & 3.48 & 41 & 53 & 77.4 & 4.73 & 55.5 & 35 \\
\hline SMA-ARC-BFFEN & 27.2 & 27.2 & 4.31 & 4.31 & 4.73 & 4.31 & 39 & 39 & 100 & 7.29 & 99.7 & 0.0 \\
\hline SMA-ARC-MOON & 38.6 & 37.9 & 4.71 & 4.56 & 4.32 & 4.64 & 62 & 64 & 96.9 & 5.94 & 86.3 & 8.3 \\
\hline SMA-ARC-RBPD & 43.7 & 43.4 & 4.46 & 4.41 & 4.43 & 4.43 & 95 & 96 & 99.0 & 6.77 & 87.7 & 0.8 \\
\hline SMA-BIG-CAP & 35.7 & 35.3 & 5.15 & 5.04 & 5.19 & 5.09 & 48 & 49 & 98.0 & 6.54 & 87.2 & 0.7 \\
\hline SMA-BUCK-PD & 24.5 & 24.5 & 4.63 & 4.63 & 4.82 & 4.63 & 27 & 27 & 100 & 5.85 & 99.7 & 0.7 \\
\hline SMA-CAR-FISH & 21.2 & 21.2 & 4.74 & 4.74 & 5.16 & 4.74 & 19 & 19 & 100 & 6.47 & 100 & 0.0 \\
\hline SMA-CAR-WLPD & 25.8 & 25.6 & 4.96 & 4.93 & 4.73 & 4.96 & 27 & 27 & 100 & 7.04 & 100 & 0.0 \\
\hline TNC-CRTR-WET1 & 22.7 & 22.7 & 4.29 & 4.29 & 4.03 & 4.29 & 28 & 28 & 100 & 6.15 & 87.8 & 3.6 \\
\hline
\end{tabular}


Table 3. Spearman rank correlation coefficients and probability values comparing various floristic measures against reference measures of freshwater wetland condition among 20 wetland sites

\begin{tabular}{|c|c|c|c|c|c|c|}
\hline \multirow[t]{2}{*}{ Index } & \multicolumn{2}{|c|}{$O I W I$} & \multicolumn{2}{|c|}{ RIRAM } & \multicolumn{2}{|r|}{$I S A$} \\
\hline & $r_{s}$ & $P$ & $r_{s}$ & $P$ & $r_{s}$ & $P$ \\
\hline$F Q A I$ & 0.24 & 0.313 & -0.08 & 0.731 & -0.09 & 0.691 \\
\hline$F Q A I_{s}$ & 0.39 & 0.092 & 0.11 & 0.642 & -0.27 & 0.253 \\
\hline Mean $C C_{n}$ & 0.75 & $<0.001$ & 0.70 & $<0.001$ & -0.70 & $<0.001$ \\
\hline Mean $C C_{s}$ & 0.82 & $<0.001$ & 0.81 & $<0.001$ & -0.84 & $<0.001$ \\
\hline Weighted Mean $C C_{s}$ & 0.82 & $<0.001$ & 0.85 & $<0.001$ & -0.86 & $<0.001$ \\
\hline$F Q A I^{\prime}$ & 0.82 & $<0.001$ & 0.78 & $<0.001$ & -0.80 & $<0.001$ \\
\hline$\%$ Native & 0.81 & $<0.001$ & 0.89 & $<0.001$ & -0.89 & $<0.001$ \\
\hline Native Species & -0.13 & 0.580 & -0.40 & 0.081 & 0.27 & 0.250 \\
\hline Total Species & -0.29 & 0.209 & -0.54 & 0.013 & 0.44 & 0.053 \\
\hline
\end{tabular}


Table 4. Kruskal-Wallace $H$-values (non-parametric analog to ANOVA) and Spearman rank correlation coefficients $\left(r_{s}\right)$ comparing measures of freshwater wetland condition against hydrogeomorphic class $(n=3)$ and unit size $(n=20)$, among 20 freshwater wetland sites

\begin{tabular}{lrrrrr}
\hline \hline & \multicolumn{2}{c}{ Hydrogeomorphic Class } & \multicolumn{2}{c}{ Site Area } \\
\cline { 2 - 3 } Index & $H$ & $P$ & $r_{s}$ & $P$ \\
\hline Floristic Index incorporating Richness & & & & \\
Native Species & 10.25 & 0.01 & 0.44 & 0.06 \\
Total Species & 7.84 & 0.02 & 0.48 & 0.03 \\
FQAI & 11.11 & $<0.01$ & 0.43 & 0.06 \\
FQAI & 10.06 & 0.01 & 0.31 & 0.18 \\
Floristic Index discounting Richness & & & & \\
Mean CC & 1.05 & 0.59 & 0.18 & 0.45 \\
Mean CC & 1.70 & 0.43 & 0.03 & 0.88 \\
Weighted Mean CC & 0.84 & 0.65 & -0.07 & 0.77 \\
FQAI' & 1.65 & 0.44 & 0.06 & 0.79 \\
\% Native & 3.74 & 0.15 & -0.28 & 0.23 \\
Reference Measure & & & & \\
OIWI & 2.28 & 0.32 & -0.07 & 0.39 \\
RIRAM & 2.91 & 0.23 & -0.30 & 0.20 \\
ISA & 1.93 & 0.38 & 0.25 & 0.29 \\
\hline
\end{tabular}


Table 5. Significant Spearman rank correlation coefficients comparing best-fit floristic measures with RIRAM metrics and submetrics among 20 wetland sites, considering a Bonferroni-adjusted critical $P$ value of $0.0036 ; \mathrm{NS}=$ not significant

\begin{tabular}{lccc}
\hline \hline & Mean CC & Weighted Mean $C_{s}$ & \%Native \\
\hline RIRAM Stress Metric & & & \\
Buffer Integrity & 0.77 & 0.76 & 0.85 \\
Surrounding Land Use Integrity & 0.85 & 0.84 & 0.89 \\
Fluvial Inputs & -0.74 & -0.77 & -0.84 \\
Filling and Dumping & -0.76 & -0.83 & -0.62 \\
Substrate Disturbance & -0.69 & -0.73 & $\mathrm{NS}$ \\
Invasive Species Cover & -0.74 & -0.73 & -0.91 \\
RIRAM Observed State Submetric & & & \\
Water and Soil Quality & 0.80 & 0.82 & 0.84 \\
Vegetation / Microhabitat Structure & 0.89 & 0.87 & 0.89 \\
Vegetation Composition & 0.72 & 0.71 & 0.90 \\
Habitat Connectivity & 0.69 & 0.72 & 0.83 \\
\hline
\end{tabular}


Table 6. Spearman rank correlation coefficients comparing reduced-effort floristic measures against existing measures of freshwater wetland condition among 20 reference wetland sites; $P<0.001$ except $* P=0.001$

\begin{tabular}{lccc}
\hline \hline & OIWI & RIRAM & ISA \\
\hline Mean $\boldsymbol{C C}_{\boldsymbol{s}}$ & & & \\
Full Sampling & 0.82 & 0.81 & -0.84 \\
Single Transect & 0.82 & 0.79 & -0.82 \\
$\geq 10 \%$ Cover & 0.74 & 0.81 & -0.79 \\
Single Transect $\geq 10 \%$ Cover & 0.77 & 0.74 & -0.78 \\
Weighted Mean $\boldsymbol{C C}_{\boldsymbol{s}}$ & & & \\
Full Sampling & 0.82 & 0.85 & -0.86 \\
Single Transect & 0.82 & 0.83 & -0.84 \\
$\geq 10 \%$ Cover & 0.79 & 0.85 & -0.82 \\
Single Transect $\geq 10 \%$ Cover & 0.80 & 0.77 & -0.80 \\
\% Native & & & \\
Full Sampling & 0.81 & 0.89 & -0.89 \\
Single Transect & 0.82 & 0.86 & -0.86 \\
$\geq 10 \%$ Cover & 0.73 & 0.70 & -0.71 \\
Single Transect $\geq 10 \%$ Cover & 0.73 & $0.67 *$ & -0.70 \\
\hline
\end{tabular}


Figure 1.
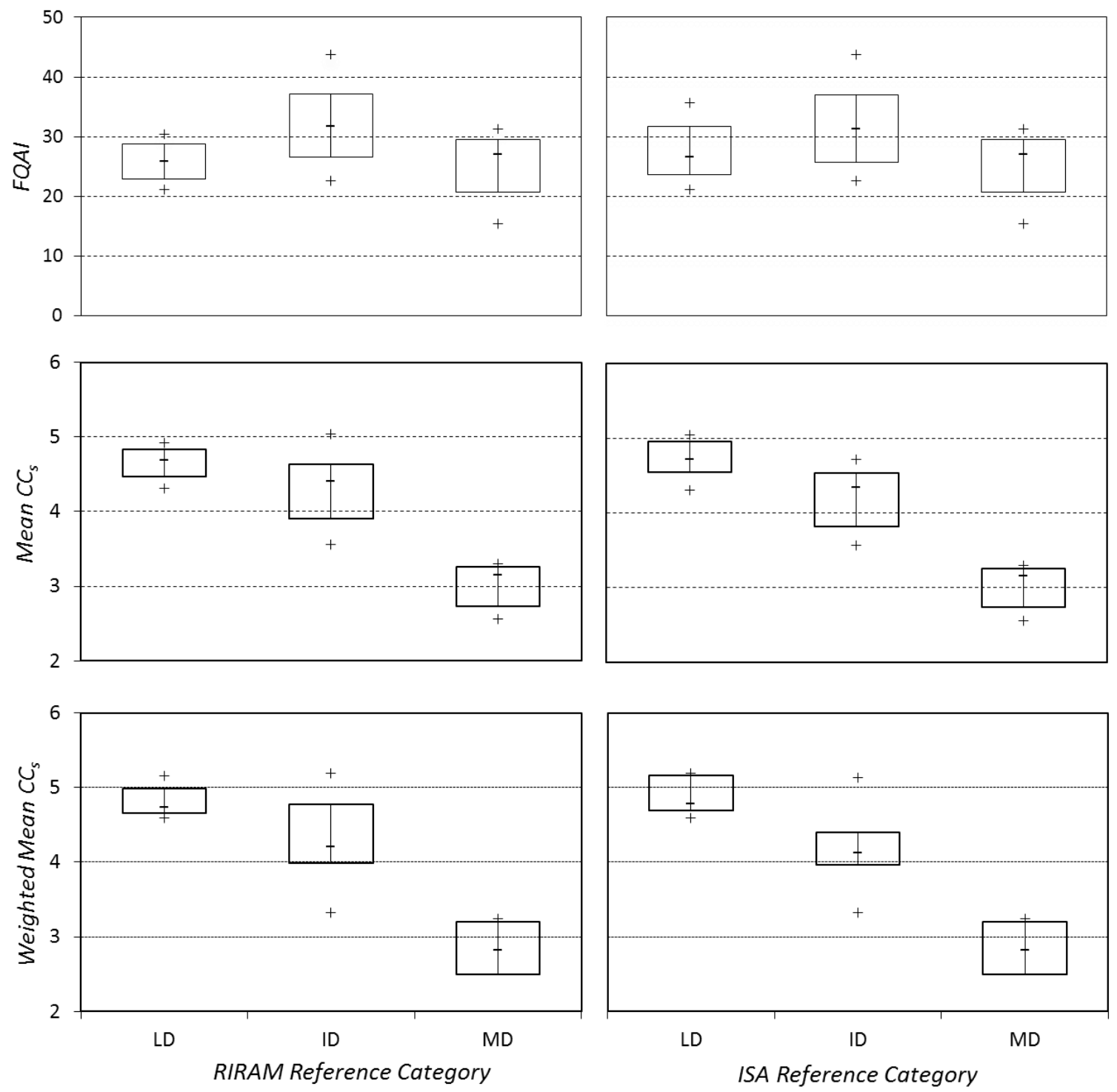

Fig. 1. Box plots depicting the distributions of FQA index values among RIRAM and ISA-based reference designations of freshwater wetland condition for 20 wetlands; boxes represent interquartile ranges, crosses represent minimum and maximum values, and dashes represent median values; $\mathrm{LD}=$ least disturbed, ID = intermediately disturbed, and MD = most disturbed 


\section{APPENDIX 1}

\section{Rhode Island Rapid Assessment Method Field Datasheet}

A. Wetland Characteristics; apply to the current state of the wetland. Not Scored.

1) Assessment Unit Area; select one:
$<<0.25$ acres
10 to $<25$ acres
0.25 to $<1.0$ acres
25 to 50 acres
1.0 to $<3.0$ acres
$>50$ acres

$\square 3.0$ to $<10$ acres

2) Hydrologic Characteristics

Source of water; select main source:
1 Precipitation
Groundwater
Surface water

Maximum water depth, today; select one:

$\square$ Dry
$\square$ Saturated
$\square<1$ foot

3) Habitat Characteristics

Water Regime; select one or two dominant regimes:
Permanently flooded
Semi-permanently flooded
Seasonally flooded
Temporarily flooded
Permanently saturated
Seasonally saturated
Regularly flooded (tidal)
Irregularly flooded (tidal)

Habitat stratum diversity; estimate total cover of all habitat strata within unit using classes at right:

Trees
Shrubs
Emergent
Aquatic bed
Sphagnum
Surface water, today
Unvegetated substrate, today
Vegetated hummocks or tussocks
Coarse woody debris
Standing dead trees
Amphibian breeding habitat

$$
\begin{aligned}
& \text { Cover Classes: } \\
& 0 \ldots . .<1 \% \\
& 1 \ldots . .1-5 \% \\
& 2 . . . .6-25 \% \\
& 3 . . . .26-50 \% \\
& 4 \ldots . .51-75 \% \\
& 5 \ldots . .>75 \%
\end{aligned}
$$

Microhabitat diversity; rate each present using the scale at right:

Ecological Significance Scale:

$$
0 \text {......None Noted }
$$

1......Minor Feature

2.....Significant Feature

3.....Dominant Feature

4) Wetland Classification

Hydrogeomorphic Class; select main one: $\quad$ NWI Classes; select all comprising unit and indicate Dominance Type:

Connected Depression

$\square$ Floodplain (riverine) $\square$ Emergent

Fringe $\square$ Aquatic Bed

$\square$ Slope $\quad \square$ Unconsolidated Bottom or Shore

$\square$ Flat $\quad \square$ Rock Bottom or Shore

RINHP natural community types; select all present within unit:
Freshwater tidal marsh*
Deep emergent marsh
Interdunal swale*
Shallow emergent marsh
Intermittent stream
Emergent fen*
Eutrophic Pond
Coastal plain pondshore*
Coastal plain quagmire*
$\square$ Dwarf shrub bog / fen*
Dwarf tree bog*
$\square$ Scrub-shrub wetland
Floodplain Forest
Red Maple Swamp
Vernal pool*
Hemlock-hardwood swamp
Atlantic white cedar swamp*
Black Spruce Bog*

5) Wetland values; select all known or observed:
$\square$ Within 100 year flood plain
$\square$ Contains known T/E species
Between stream or lake and human use
Significant avian habitat
Part of a habitat complex or corridor
Contains GCN* habitat type
$\square$ Falls in aquifer recharge zone
$\square$ Educational or historic significance

entified by DEM as habitat of Greatest Conservation Need 
B. Landscape Stresses. Sum metrics 1 and 2

\section{1) Degradation of Buffers}

Estimate \% cultural cover within 100-foot buffer. Select one.

$<5 \%(10)$

6 to $25 \%(7)$

$26-50 \%(4)$

$51-75 \%(1)$

$>75 \%(0)$

2) Intensity of Surrounding Land Use

Land Use Intensity weighted average within 500-foot buffer. Estimate proportion of each class to the nearest tenth and multiply. Proportion Score Weighted Value

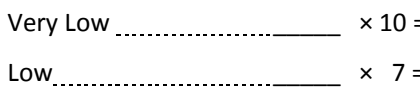

Moderately High _......___ $\times 4=$

High $\ldots \ldots \ldots \ldots \ldots \ldots \ldots \ldots \ldots$

Sum weighted values for score $=$
Associated Stressors: Check all that apply

Commercial or industrial development Unsewered Residential development Sewered Residential development New construction

Landfill or waste disposal

Channelized streams or ditches

Raised road beds

Foot paths / trails

Row crops, turf, or nursery plants

Poultry or livestock operations

Orchards, hay fields, or pasture

Piers, docks, or boat ramps

Golf courses / recreational development

Sand and gravel operations

Other

\section{Very Low........Natural areas, open wate}

Low.................Recovering natural lands, passive recreation, low trails/dirt roads

Mod High.......Residential, pasture/hay, mowed areas, raised roads to 2-lane

High................Urban, impervious land cover, new construction, row crops, turf crops, mining operations, paved roads $>2$-lane

Sum of Metrics 1 and $2=$

\section{B. Landscape Stress Score}

C. Wetland Stresses. Sum metrics 3 to 9 and subtract from 70 .

3) Impoundment.

\begin{tabular}{|c|c|}
\hline \multirow{2}{*}{\multicolumn{2}{|c|}{$\begin{array}{l}\text { Sum } a \text { and } b(\operatorname{Max}=10) \\
\text { a. Increase in depth or hydroperiod. Select one } \\
\text { and multiply by the proportion of the unit } \\
\text { affected to the nearest tenth. = }\end{array}$}} \\
\hline & \\
\hline$\square$ & None $(0)$ \\
\hline$\square$ & Wetland was created by impoundment ( 1 \\
\hline$\square$ & Change in velocity only (2) \\
\hline$\square$ & Change of less than one water regime (4) \\
\hline$\square$ & Change of one water regime (6) \\
\hline$\square$ & Change of two or more water regimes (8) \\
\hline$\square$ & Change to deepwater (10) \\
\hline
\end{tabular}

Proportion of unit affected (circle one)

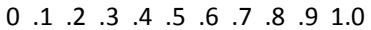

b. Artificial barrier to movement of resources through water.

Select all that apply and sum. =

None (0)

Barrier to upstream movement at low water (1)

Barrier to downstream movement at low water (1)

Barrier to upstream or downstream movement above low water (1)

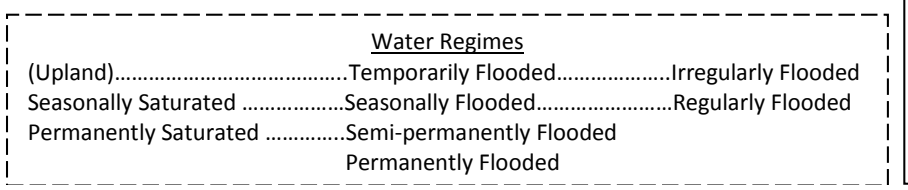

Evidence: check all that apply

Physical barrier across flow downstream of wetland

Abrupt and unnatural edge downstream of wetland

Dam or restricting culvert downstream of wetland

Deepening of wetland upstream of barrier

Widening of wetland upstream of barrier

Change in vegetation across barrier

Dead or dying vegetation

Primary Associated Stressor

check one:

Road

Railway

$\checkmark$ Weir / Dam

$\checkmark$ Raised Trail

Development Fill

$\square$ Other

Primary Source of Stress

indicate as current $(\mathrm{C})$ or

historic $(\mathrm{H})$ :

_ Private / Residential

Commercial

Agricultural

- Public transportation

Public utilities

- Public recreation

Undetermined 
4) Draining or diversion of water from wetland. Decrease in depth or hydroperiod. Select one and multiply by the proportion of the unit affected to the nearest tenth.

None (0)

Change in velocity only (3)

Change of less than one water regime (5)

Change of one water regime (7)

Change of two or more water regimes or to upland (10)

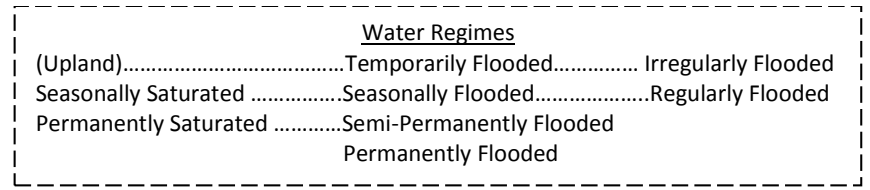

idence: check all that apply

Drainage ditches or tiles evident

Evident impoundment upstream of wetland

Severe root exposure

Moderate root exposure

Soil fissures

Uncharacteristically dry groundcover

Dead or dying vegetation

Change in vegetation across barrier

Proportion of unit affected (circle one)

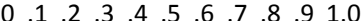

5) Anthropogenic fluvial inputs.

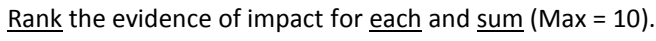

a. Nutrients

b. Sediments / Solids

c. Toxins / Salts

d. Increased flashiness

\begin{tabular}{|l|} 
Primary Associated Stressor; \\
Check one: \\
$\square$ Road \\
$\square$ Railway \\
$\square$ Dike \\
$\square$ Fill \\
$\square$ Drainage ditch / tile \\
$\square$ Major well withdrawals \\
$\square$ Surface water pumps \\
$\square$ Other
\end{tabular}

Primary Source of Stress indicate as current $(\mathrm{C})$ or historic $(\mathrm{H})$ :

Private / Residentia

_ Commercial

_ Agricultural

_ Public transportation

_ Public utilities

Public recreation

_ Undetermined

Evidence: check all that apply

Runoff sources evident

Point sources evident

Excessive algae or floating vegetation

Excessive rooted submerged or emergent vegetation

Uncharacteristic sediments

Obvious plumes or suspended solids

Chemical smell

Strangely tinted water

Dead, dying, or patchy vegetation

Dead fauna or stark lack of life

Root exposure or bank erosion due to scouring

\section{Evidence-of-Impact Ranks \\ 0 ......No evidence \\ 1.....Sources evident, only \\ 3.....Slight impact evident \\ 5.....Moderate to strong impact evident}

Primary Source of Stress;

indicate as current $(\mathrm{C})$ or historic $(\mathrm{H})$ :

Check one:

Point runoff

Sheet runof

Effluent discharge

Organic / yard waste

Other point

Riverine (up-stream)

Multiple / non-point

Channelization
_ Private / Residentia

Commercial

_ Agricultural

_Public transportation

Public utilities

_Public recreation

- Multiple / non-point

_ Undetermined

6) Filling and dumping within wetland. Select one and multiply by the proportion of the unit affected to the nearest tenth (Max = 10).

$\square \quad \begin{aligned} & \text { Intensity of filling } \\ & \square \quad \text { None (0) }\end{aligned}$

Proportion of unit (or perimeter) affected (circle one)

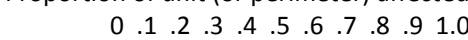

Affects aesthetics only (2)

Affects water regime, vegetation, or soil quality (6)

Changes area to upland (10)

Fill is above surrounding upland grade (12)

\footnotetext{
Evidence: check all that apply

Unnaturally abrupt change in ground level

Abrupt change in soil texture or content

Unnaturally straight or abrupt wetland edge

Unnatural items on or within the sediments
}

Primary Associated Stressor;
Check one:
$\square$ Road
$\square$ Raised Trail
$\square$ Railway
$\square$ Trash
$\square$ Fill
$\square$ Organic / yard waste
$\square$ Dam
$\square$ Dike
$\square$ Other

Primary Source of Stress; indicate as current $(\mathrm{C})$ or historic $(\mathrm{H})$ :

_ Private / Residential

Commercial

_ Agricultural

Public transportation

Public utilities

_ Public recreation

Undetermined 
7) Excavation and other substrate disturbances within wetland. Select one and multiply by the proportion of the unit affected to the nearest tenth.

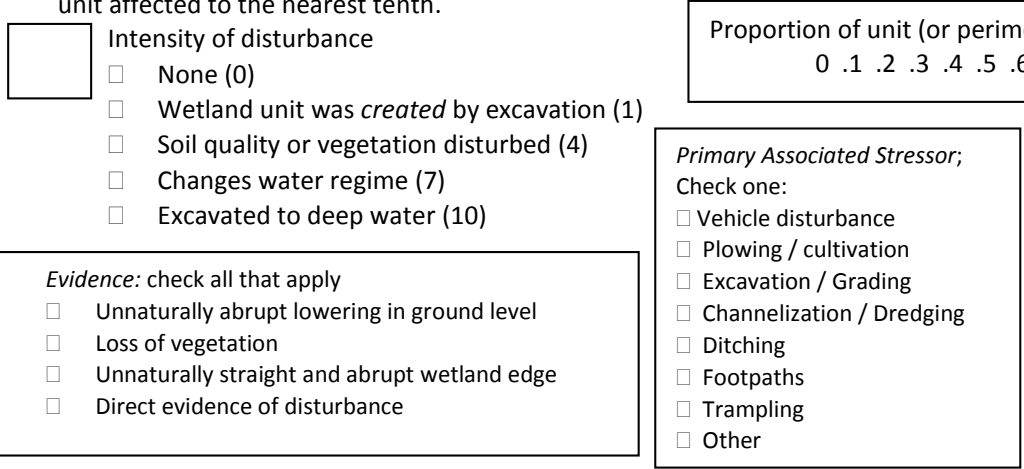

Proportion of unit (or perimeter) affected (circle one)

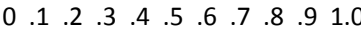

8) Vegetation and detritus removal within wetland. Rank extent and multiply by the estimated proportion affected for each layer; then sum ( $\mathrm{Max}=10)$.

\begin{tabular}{|c|c|c|}
\hline & Layers affected & Extent Proportion \\
\hline & $\square \quad$ Aquatic Bed & $\ldots=$ \\
\hline & $\square \quad$ Detritus & $x$ \\
\hline & Emergent & $x_{-}$ \\
\hline & $\square \quad$ Shrub & $x$ \\
\hline & $\square \quad$ Canopy & $x$ \\
\hline \multirow{5}{*}{\multicolumn{2}{|c|}{$\begin{array}{l}\text { Evidence: check all that apply } \\
\square \text { Cut stems or stumps } \\
\square \quad \text { Immature vegetation strata } \\
\square \text { Missing vegetation strata } \\
\square \text { Mowed areas } \\
\square \text { Browsing or grazing }\end{array}$}} & Sur \\
\hline & & Extent of removal \\
\hline & & 0......None \\
\hline & & 2.....Partial or recovering \\
\hline & & 3......Complete \\
\hline
\end{tabular}

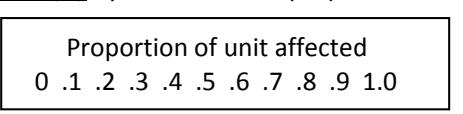

\begin{tabular}{|c|c|}
\hline $\begin{array}{l}\text { Primary Associated Stressor; } \\
\text { Check one: } \\
\square \text { Power lines } \\
\square \text { Grazing } \\
\square \text { Cultivation } \\
\square \text { Timber Harvest } \\
\square \text { Development clearing } \\
\square \text { Trails / non-raised roads } \\
\square \text { Excavation / ditching } \\
\square \text { Other }\end{array}$ & $\begin{array}{l}\text { Primary Source of Stress, } \\
\text { indicate as current }(\mathrm{C}) \text { or } \\
\text { historic }(\mathrm{H}) \text { : } \\
\text { _ Private / Residential } \\
\text { _ Commercial } \\
\text { - Agricultural } \\
\text { _ Public transportation } \\
\text { _- Public utilities } \\
\text { - Public recreation } \\
\text { _ Undetermined }\end{array}$ \\
\hline
\end{tabular}

9) Invasive species within wetland.

\begin{tabular}{|c|c|}
\hline & $\begin{array}{l}\text { Select one class for total coverage. } \\
\text { None noted }(0)\end{array}$ \\
\hline$\square$ & Nearly absent $<5 \%$ cover $(2)$.............. Cover Class 1 \\
\hline$\square$ & Low $6-25 \%$ cover (4) ............................ Cover Class 2 \\
\hline$\square$ & Moderate $26-50 \%$ cover $(6)$................Cover Class 3 \\
\hline$\square$ & High $51-75 \%$ cover (8)............................ Cover Class 4 \\
\hline$\square$ & Extensive $>75 \%$ cover $(10) \ldots$ \\
\hline
\end{tabular}

9b. List and select a cover class for each invasive plant species noted.

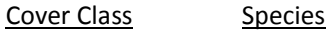

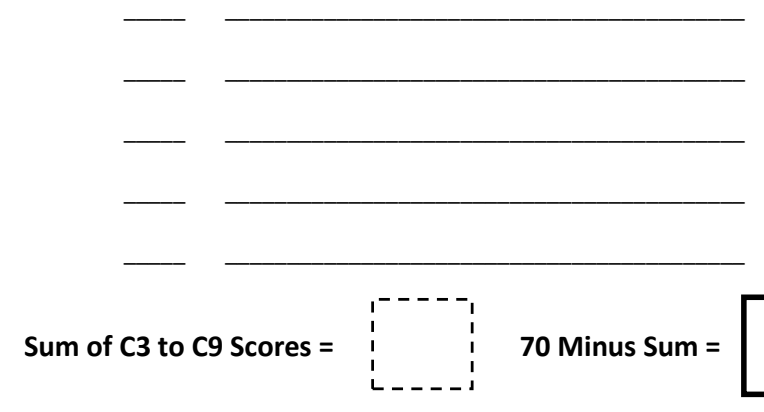

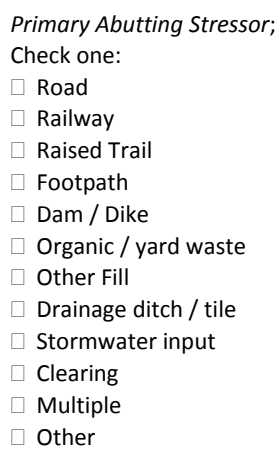

Primary Source of Stress; indicate as current (C) or historic $(\mathrm{H})$ :

_ Private / Residential _ Public transportation

- Commercial

_ Agricultural

_ Undetermined
Primary Source of Stress; historic $(\mathrm{H})$ :

_ Private / Residential

Commercial

Public transportation

Public utilities

Public recreation

Undetermined 
D. Observed State of Wetland Characteristics. Circle one score for each characteristic and sum. Refer to Sections A through C to inform scores. Consider current wetland types.

\begin{tabular}{|c|c|c|c|c|}
\hline Characteristics & Characteristic & Degraded & & \\
\hline Hydrologic Integrity... & 1.5 & 1 & 0.5 & \\
\hline 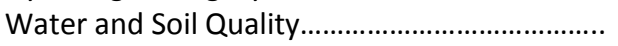 & 1.5 & 1 & 0.5 & \\
\hline Vegetation/microhabitat Structure ....................... & 1.5 & 1 & 0.5 & \\
\hline 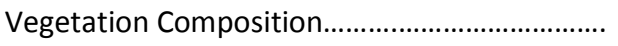 & 1.5 & 1 & 0.5 & \\
\hline 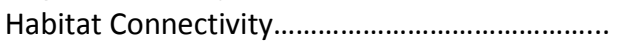 & 1.5 & 1 & 0.5 & \\
\hline
\end{tabular}

SUM $=\square$ D. Observed State Score

B. Landscape Stress Score $(\max 20)$

C. Wetland Stress Score $(\max 70)$

B+C. Total Stress Score $(\max 90)$

D. Observed State Score $(\max 10)$

RIRAM V. 2.10 Condition Index

\section{$+$} $=$

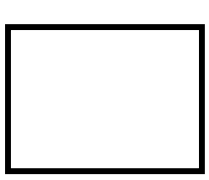

$=$

* Characteristic of wetland type in an unstressed setting 